\title{
Living with bark beetles: impacts, outlook and management options
}

Tomáš Hlásny, Paal Krokene, Andrew Liebhold, Claire Montagné-Huck, Jörg Müller, Hua Qin, Kenneth Raffa, Mart-Jan Schelhaas,

Rupert Seidl, Miroslav Svoboda and Heli Viiri 


\section{AUTHORS}

Tomáš Hlásny, Czech University of Life Sciences in Prague, the Czech Republic

Paal Krokene, Norwegian Institute of Bioeconomy Research, Norway

Andrew Liebhold, Czech University of Life Sciences in Prague, the Czech Republic

Claire Montagné-Huck, Université de Lorraine, Université de Strasbourg, AgroParisTech, CNRS, INRA,

BETA, France

Jörg Müller, Julius-Maximilians-University Würzburg, Bavarian Forest National Park, Germany

Hua Qin, University of Missouri-Columbia, USA

Kenneth Raffa, University of Wisconsin - Madison, USA

Mart-Jan Schelhaas, Wageningen Environmental Research, Wageningen University and Research, Netherlands

Rupert Seidl, University of Natural Resources and Life Sciences, Vienna, Austria

Miroslav Svoboda, Czech University of Life Sciences in Prague, the Czech Republic

Heli Viiri, Natural Resource Institute, Finland

\section{ACKNOWLEDGEMENTS}

The report benefited from the helpful comments from external reviewers, Marc Hanewinkel (University of Freiburg), Johanna Witzell (Swedish University of Agricultural Sciences) and Georg Winkel (European Forest Institute). We wish to express our thanks for their insights and comments that helped to improve the report, and acknowledge that they are in no way responsible for any remaining errors.

This work and publication has been financed by EFI's Multi-Donor Trust Fund for policy support, which is supported by the Governments of Austria, Czech Republic, Finland, Germany, Ireland, Italy, Lithuania, Norway, Spain and Sweden.

ISSN 2343-1229 (print)

ISSN 2343-1237 (online)

ISBN 978-952-5980-75-2 (print)

ISBN 978-952-5980-76-9 (online)

Editor in chief: Lauri Hetemäki

Managing editor: Rach Colling

Layout: Grano Oy

Disclaimer: The views expressed in this publication are those of the authors and do not necessarily represent those of the European Forest Institute, or of the funders.

Recommended citation: Hlásny, T., Krokene, P., Liebhold, A., Montagné-Huck, C., Müller, J., Qin, H., Raffa, K., Schelhaas, M-J., Seidl, R., Svoboda, M., Viiri, H. 2019. Living with bark beetles: impacts, outlook and management options. From Science to Policy 8. European Forest Institute. https://doi.org/ $10.36333 /$ fs08 


\section{Contents}

Executive summary.... 4

1. Purpose and background: Europe's forests under intensifying bark beetle outbreaks............... 6

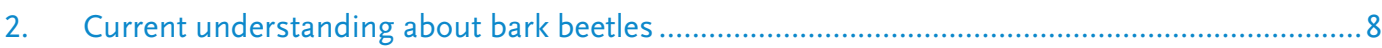

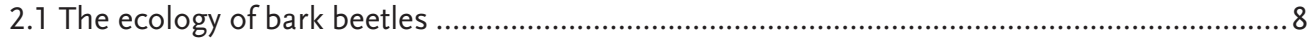

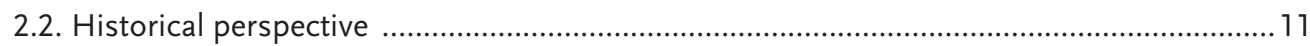

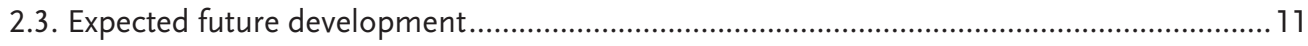

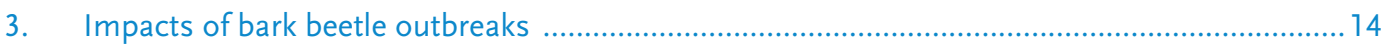

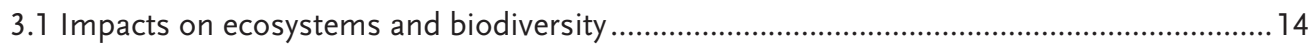

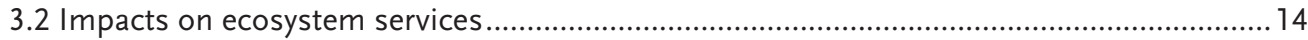

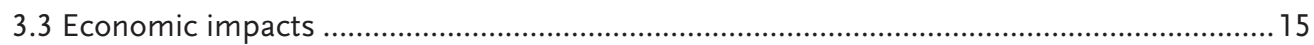

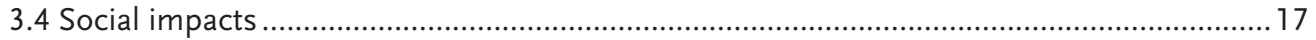

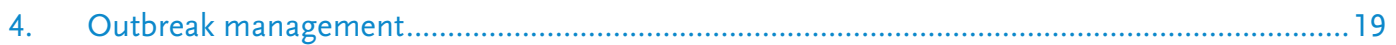

4.1 Multifunctional and production forests ........................................................................ 19

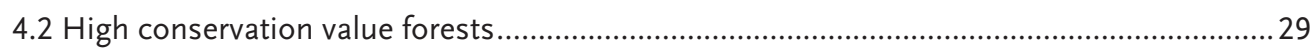

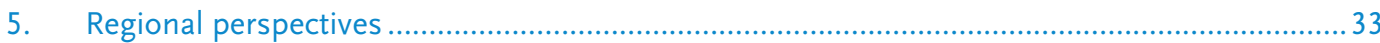

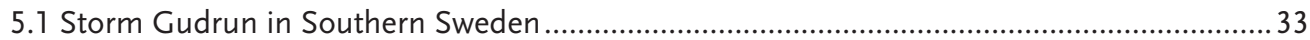

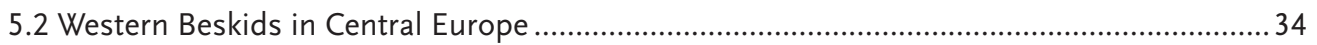

5.3 Mountain pine beetle in the Rocky Mountains of North America ...................................... 35

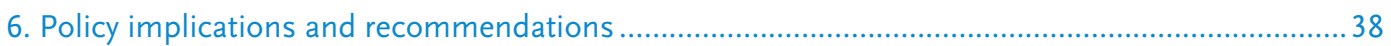

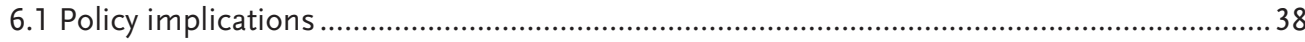

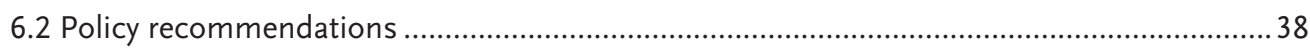

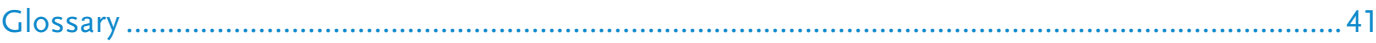

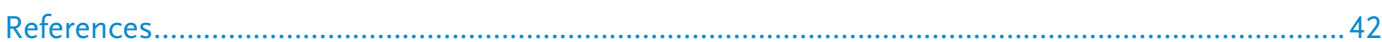

Appendix A: Tools and measures for managing bark beetle outbreaks .............................................4 45

Appendix B: Research, development and innovation needs...........................................................50 
E urope's forests have provided human societies with essential ecosystem services and great economic values for centuries. Some of these values are now increasingly threatened by climate change, which greatly intensifies forest disturbances such as bark beetle outbreaks. However, some past management practices have also increased the vulnerability of Europe's forests. For example, due to its good growth performance and favourable properties for forest industry, Norway spruce has been planted extensively in Europe over the past century, including in areas outside its native range. This has created large areas of so-called secondary forests, which have increasingly exhibited problems with health and vitality and are prone to various disturbances: the most important being wind, drought and bark beetles.

This report aims to help European and national policy makers understand the complex roles bark beetles play in our forests, and provide the scientific basis for robust forest policies and management options to address these emerging bark beetle problems.

\section{Bark beetles impact forest ecosystems and society}

Bark beetles are a diverse group of insects with a worldwide distribution. The overwhelming majority of bark beetle species breed only in dead trees and tree parts, and play a valuable role in nutrient cycling and as food for other animals. However, a few outbreaking species - in Europe primarily the spruce bark beetle Ips typographus - colonize stressed and dying trees when their populations are low, but then mass-attack large numbers of healthy trees once their populations are high. These outbreaking species are the ones of most concern to forestry, and have landscape-scale social, economic and ecological consequences.

There has been an alarming increase in impacts of bark beetle outbreaks in conifer forests in recent years, for example in Austria, Czech Republic, Germany and Slovakia and also in North America. These outbreaks have profound and long-lasting impacts on forest ecosystems, which range from highly positive (fostering biodiversity) to highly negative (reducing carbon storage or disrupting timber supply). Outbreaks also affect regional economies, markets and employment, as well as social values. Some recent outbreaks and efforts to manage them have even led to political conflicts and social unrest.

\section{Climate change intensifies bark beetle outbreaks}

Synchronized by extreme weather, recent bark beetle outbreaks have already reached a supranational scale. Outbreaks are likely to further increase in extent and severity in the future due to climate change. For example, it accelerates development of bark beetles, reduces tree defence abilities and facilitates beetles' expansion to new territories. These increases are expected to come in waves, which will be triggered by cyclonic storm events or large-scale droughts, and are likely to occur simultaneously over large areas.

\section{Tailor-make management strategies for bark beetle outbreaks}

This report outlines outbreak management strategies for two different types of European forests: those in which wood production is a key objective, and forests where the conservation of biodiversity, natural processes and other conservation values are a high priority. Obviously, many intermediate variants between these two categories can be found in forest management legislation and practice in Europe. The report critically evaluates a comprehensive list of available management measures, and provides recommendations on their use as tailor-made outbreak management frameworks for different local management objectives and conditions. 


\section{Policy recommendations}

\section{Clearly define local management objectives}

Whether bark beetle outbreaks are considered to be damaging or providing benefits strictly depends on local management objectives. To reduce the probability of societal conflicts and increase the legitimacy of management objectives, they need to be explicitly defined in close collaboration with diverse stakeholders. Research on the social dimensions of bark beetle outbreaks, which is currently lacking in Europe, is required to effectively involve local communities and other stakeholders in this process. Improved education and communication programmes at all administrative levels are also needed to disseminate new information and rectify possible misconceptions about natural disturbances.

\section{Strengthen European-level coordination}

Strengthened international collaboration on forest protection, pest monitoring and forest management is needed to manage large-scale outbreaks. Crosssectoral crisis management plans (e.g. including the forestry, environment, finance, transportation and public safety sectors) are necessary to mitigate the adverse effects of outbreaks for forest owners and society. Coordinated European platforms such as the EFI Risk Facility can provide efficient support in their development as well as synthesising and disseminating the most updated scientific information.

\section{Adopt a holistic, landscape-scale approach}

Effective management of bark beetle outbreaks requires an integrated management framework that includes monitoring, sanitation, silviculture and non-intervention. The main elements are:

- Placing a balanced emphasis on risk reduction and outbreak prevention approaches, which have dominated forest management in Europe, and management measures that foster forest resilience, i.e. the ability of forest to recover after disturbance.
- Supporting disturbance management at the landscape level, for example to disrupt the connectedness of beetle populations and host trees across the landscape and prevent the spread of bark beetles. This requires improved coordination and communication between forest owners (e.g. via owner associations).

- Adopting legislation that supports the implementation of a broader spectrum of forest protection methods and measures, to increase flexibility to develop bark beetle management strategies tailored to specific management objectives and environments.

- Relaxing legal constraints on forest management that interfere with a more comprehensive approach to disturbance management. The requirement that disturbed sites must be regenerated within a short time window, for instance, often leads to the creation of homogeneous and evenaged young stands, which are again highly susceptible to future natural disturbances.

- Updating the current understanding of sanitation and salvage logging, and mass trapping of beetles in the view of the emerging scientific understanding of their effectiveness (or lack thereof). This can prevent, for example, inefficient use of resources, collateral impacts of salvage operations and misuse of existing policy instruments (such as reduced tax on logs from sanitation logging).

- Facilitating the sharing of data on pests and diseases collected by national forest protection agencies and similar bodies, and creating a consistent international monitoring system for bark beetles in Europe. 


\section{Purpose and background: Europe's forests under intensifying bark beetle outbreaks}

This report was prepared in response to the alarming increase in impacts of bark beetle outbreaks in Europe's conifer forests. It aims to inform policies on how to adequately respond to an expected intensification of bark beetle disturbances, as well as to the social and political conflicts caused by some recent outbreaks and the efforts to manage them. The study critically reviews current approaches to managing outbreaks in forests with different management objectives and histories. Recent outbreaks and their management have also caused contradictory reactions among forest professionals, ecologists and other stakeholders. This report aims to provide insights into the reasons underlying these different views, and develop informed responses that may help to reconcile this disparity.

Europe's forests have provided human societies with essential ecosystem services and great economic values for centuries. One consequence of the good growth performance and favourable technical properties of one valued species, Norway spruce, has been the extensive planting of this conifer in areas outside its native range. This was done at the expense of other, mostly broadleaved, native species. Repeated off-site planting of several generations of spruce, sometimes using foreign reproductive material, has resulted in the presence of large areas of so-called secondary forests. These forests have increasingly exhibited problems with health and vitality and are prone to various disturbances, the most important being wind, bark beetles and drought. This situation has been dramatically worsened by climate change, which has further compromised tree defence abilities and favoured bark beetles. These effects are amplified by the relatively homogenous structure of most secondary forests, which facilitates bark beetle reproduction and spread. Hence, the combination of off-site planting and climate change has in many regions pushed spruce towards or beyond the margin of its persistence. Recent events have also indicated that spruce forests experience an increased disturbance risk even within their native range.

Bark beetle outbreaks have profound and long-lasting impacts on forest ecosystems. Depending on the way that forests are valued, bark beetles can be regarded as natural disturbance agents that contribute to normal ecosystem functioning, or as costly competitors for our desired resources and economic well-being. The impacts of outbreaks could thus be perceived as ranging from highly positive (e.g. fostering biodiversity) to highly negative (e.g. reducing provisioning and regulating ecosystem services such as carbon storage and water purification, or disrupting flows of timber and biomass). Outbreaks also affect regional economies and markets via a range of cascading processes. These include, for example, temporary impacts on roundwood markets (e.g. oversupply, timber price decline), impacts on non-market values and tourism, and reduced carbon sink, but also increased demands for forestry workers with effects on regional employment.

Bark beetle outbreaks also often affect human social values. In severe cases outbreaks may cause hazardous falling tree conditions, aesthetic loss, reduced capacity for protection from gravitation hazards, ruined trail conditions, property value loss, land use conflicts or loss of community identity. Although the current understanding of the social aspects of forest disturbances is limited, there is an increasing need to address these aspects related to forest management and other activities.

There are remarkable temporal and geographical differences within Europe in the perception of forest disturbances and approaches to manage bark beetle outbreaks. For example, in high conservation value forests, some policy makers and a portion of the public perceive outbreaks as a step towards restoring 'authentic wilderness' and as a chance to create natural laboratories to observe and study ecosystem recovery processes (Müller 20II). Yet many others perceive the same post-disturbance conditions as 'dead forests' and a failure of proper management. Differences arise in managed forests as well. For example, Scandinavian countries have increasingly abandoned efforts to contain bark beetle outbreaks by intensive management operations, either because of doubts about efficacy or because management was found to have problematic environmental impacts. While 600,000 traps were used in southern Norway during the 1977-198I spruce bark beetle outbreak, today only c. 500 traps 
are deployed, for monitoring purposes only. By contrast, in some central and eastern European countries mass-trapping and salvage felling are still extensively used in attempts to control outbreaks, with 40,000 traps in use annually in Slovakia, 35,000 in the Czech Republic and I5-30,000 in Romania (Galko et al. 2016). At the same time, salvage and sanitation logging spans thousands of hectares and frequently exceeds $50 \%$ of the total annual harvest in these countries.

These great disparities in the perception of bark beetle outbreaks and their management illustrate the challenge of providing generally applicable recommendations to support forest management and conservation across the diverse ecological, social, historical and political landscape of Europe. Other difficulties emerge from the limited documentation and scientific understanding of the efficiency of traditional forest protection measures and what future disturbance dynamics will be like. It is obvious, however, that many of these uncertainties will remain unresolved for many years, and it is therefore not practical to wait to formulate policy recommendations until we have a more advanced scientific understanding. Therefore, we write this report based on the best current available science and explicitly point out any knowledge gaps that underlie our recommendations.

This report is particularly aimed at European and national policy makers to help them better understand the complex roles bark beetles play in our forests, and provide the scientific basis for robust forestry policies addressing emerging bark beetle problems. We also list the main knowledge gaps regarding bark beetle impacts and management to identify priorities for future research funding. Finally, the report can guide all levels of forestry education on how to adapt their teaching to better reflect the current understanding about bark beetles, their impacts and management options. 


\section{Current understanding about bark beetles}

The scientific understanding of bark beetles and how they interact with their environment has advanced significantly in recent decades. While the scientific community actively uses and shares this information, knowledge transfer to policy and decision makers, including forest managers, lags behind the scientific understanding. We therefore summarize the current understanding about bark beetles, to allow for a better comprehension of the policy recommendations in Chapter 6 .

\subsection{The ecology of bark beetles}

Bark beetles are a diverse group of insects with a worldwide distribution. The overwhelming majority of the world's roughly 6,000 bark beetle species breed only in dead trees and tree parts, and thus play valuable roles in nutrient cycling and as food for other animals. However, some species affect forests because they mass-attack and breed in the main stems of conifers. Some of these species may colonize living trees, but only severely stressed trees that have reduced resistance to attack. However, a few problematic species colonize stressed and dying trees when their populations are low, but then mass-attack large numbers of healthy trees once their populations are high. These outbreaking species are the ones of most concern to forestry, and have landscape-scale social, economic and ecological consequences.

The highest number of outbreaking, tree-killing species occurs in North America. In Europe, the primary outbreak species is the widely distributed spruce bark beetle, Ips typographus, whose range largely corresponds to that of its spruce hosts. Several other bark beetle species, attacking mainly spruce, can be regionally important in Europe under some circumstances. These species, which overlap with and may attack trees together with Ips typographus, include the double-spined bark beetle Ips duplicatus, the eight-toothed spruce bark beetle Ips amitinus and the six-toothed spruce bark beetle Pityogenes chalcographus. The main focus of this report is on Ips typographus, but our recommendations are valid also for most other tree-killing bark beetle species in Europe.

Adult bark beetles enter the bark, construct small chambers in the inner bark and attract mates. After copulation, females construct long galleries along which they lay eggs. If a high number of beetles attack the same tree, mated females may re-emerge and establish so-called sister broods in trees that are

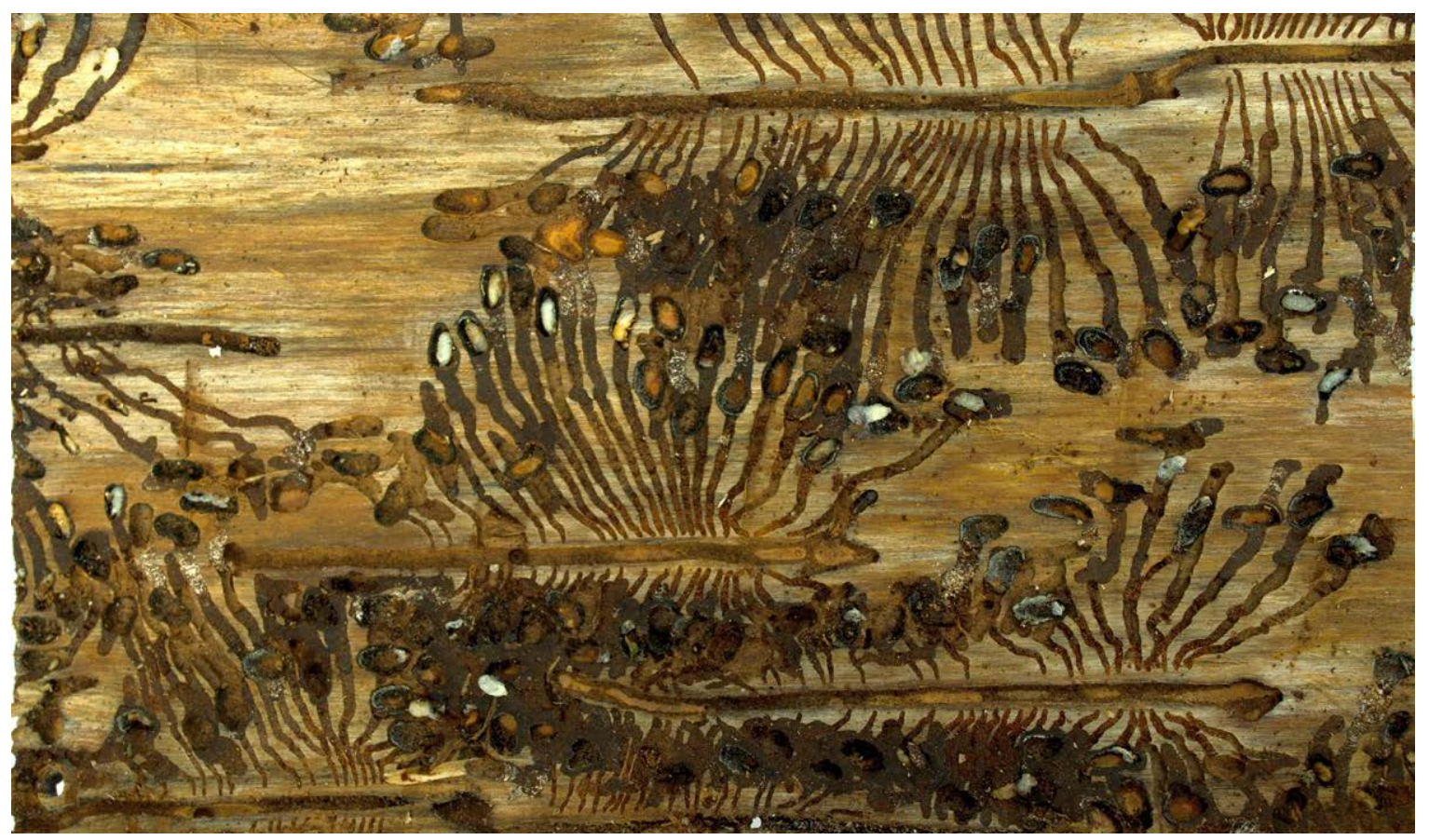

Figure 1. Galleries of the spruce bark beetle Ips typographus with larvae. Photo: Roman Modlinger. 
less crowded with competitors. The larvae hatch, and make feeding tunnels away from the female gallery. Following pupal and callow adult stages, the new mature adults emerge from the tree and disperse to hibernation sites if the population is univoltine (completes one generation per year). If the population completes more than one generation per year, as Ips typographus does in large parts of Europe, the adults emerge, attack new trees and repeat the process. Beetle development rates, and sometimes the number of generations per year, increase with temperature and are expected to increase in response to climate change.

Successful beetle colonization of a healthy tree is typically fatal, because hundreds of beetle attacks destroy the inner bark and disrupt nutrient transport to the roots. The beetles also infect the trees with pathogenic fungi that eventually block water transport in the sapwood. Each tree-killing bark beetle species is commonly able to breed in only one genus of trees and can exploit a tree for only one generation before the resources in the bark are exhausted. The number of offspring produced increases with the tree diameter and bark thickness. Under optimal conditions bark beetle populations can increase more than I5-fold from one generation to the next, translating into a theoretical 225 -fold increase in beetle numbers from one year to the next for populations completing two generations per year.

Most bark beetles are associated with microorganisms, especially so-called bluestain fungi and bacteria. These associations range from more casual and variable relationships, where the microorganisms mainly use the beetles as a means of transport, to very specific mutualistic relationships where both partners benefit from the interaction. Bluestain fungi and other microorganisms can help the beetles by providing nutrients to the larvae, enhancing the beetles' ability to overcome tree defences, protecting them from pathogens and increasing their tolerance to cold temperatures. Bark beetles also have a number of natural enemies such as predators (primarily woodpeckers, beetles, flies, mites), parasites (wasps, nematodes) and pathogens. These kill a portion of each bark beetle generation during development and dispersal. Tree-killing species also suffer high losses when they breed in dead trees, due to competing insects that specialize on this resource.

Trees have sophisticated chemical, anatomical, and physiological defences that enable them to resist attack by bark beetles most of the time. Examples of tree defences include necrotic lesions that form around beetle attacks in the bark, combined with the production of terpenes and other toxic chemicals. These defences can be lethal to adult

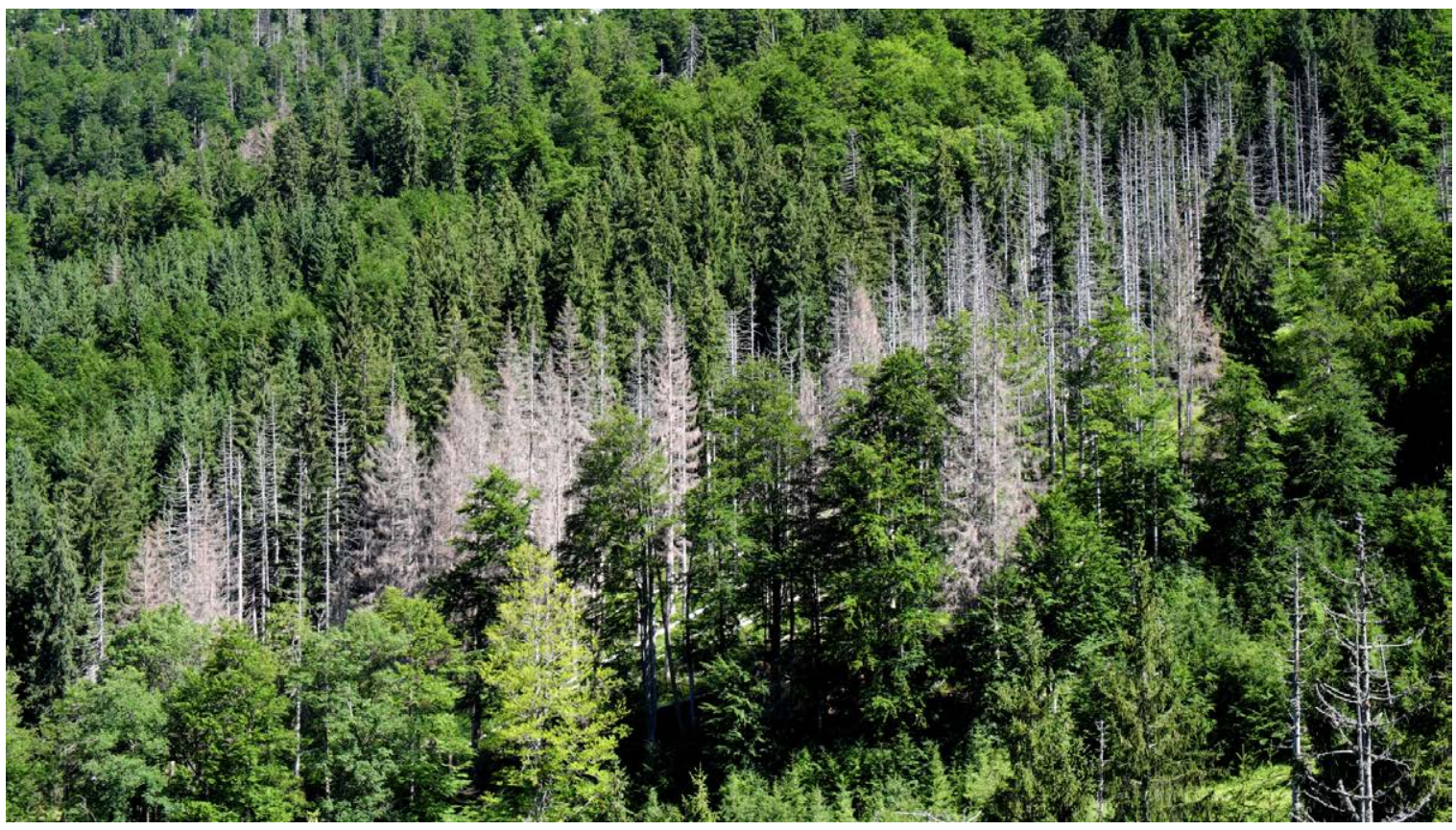

Figure 2. Norway spruce trees killed by the spruce bark beetle, Austria, Northern Front Range of the Alps. Photo: Rupert Seidl. 

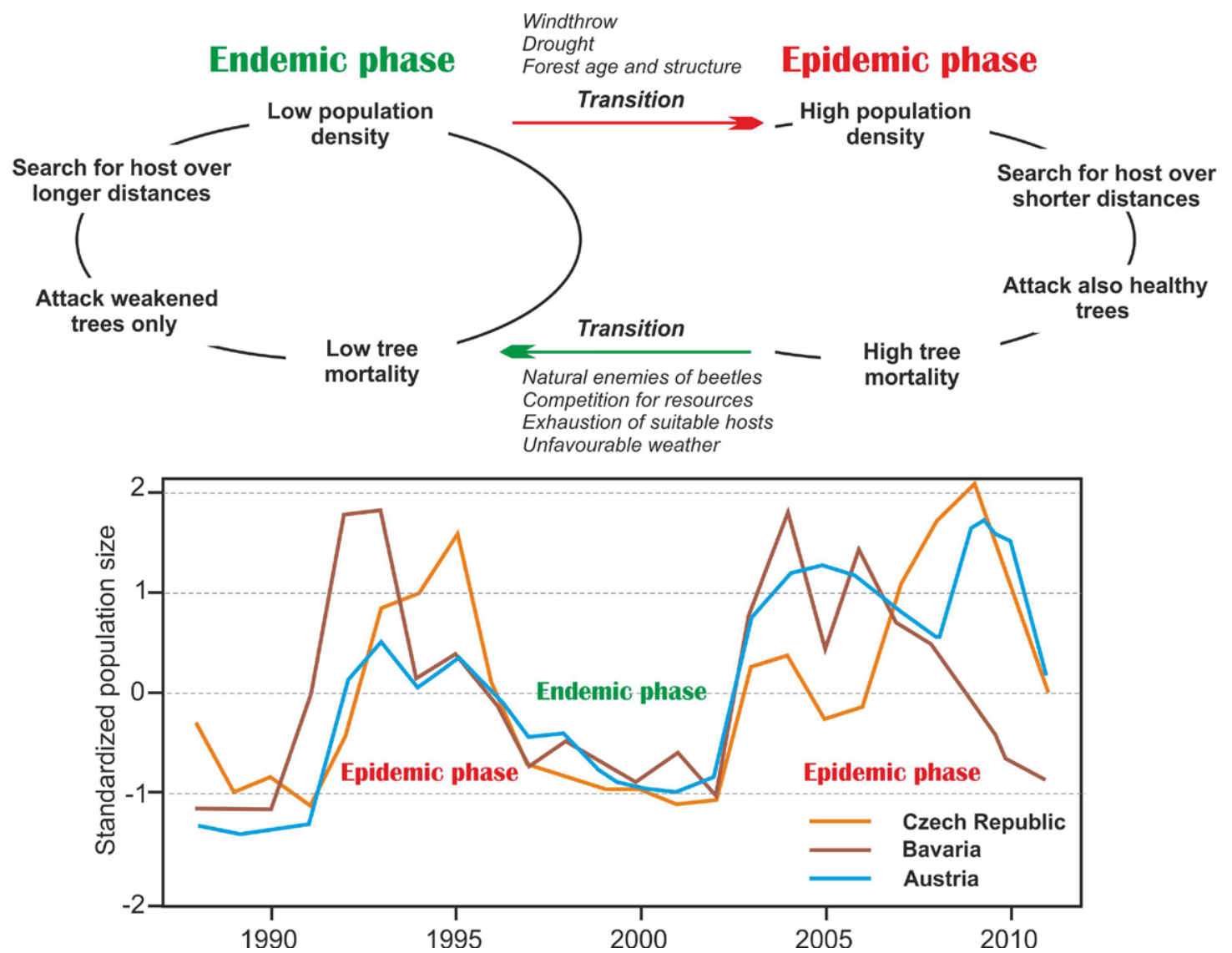

Figure 3. Scheme of bark beetle population dynamics. Low and stable bark beetle populations (endemic phase) can be periodically disrupted by external factors such as droughts and windthrows, which trigger a transition to the epidemic phase (upper panel, adopted from Kautz et al. 2014). For Ips typographus, the epidemic phase typically lasts several years. Population decrease and transition back to the endemic phase (outbreak collapse) is driven by factors such as natural enemies and competition for resources, but also by unfavourable weather or the exhaustion of suitable host trees. The bottom graph shows the transition between endemic and epidemic phases over time during synchronous Ips typographus outbreaks in the Czech Republic, Bavaria (Germany) and Austria. Population values have been standardized for comparison across regions (adopted from Seidl et al. 2014).

beetles, their offspring and the beetles' fungal associates. Beetles have two major ways of reproducing despite these tree defences. They can avoid defences by only entering trees that are already dead, such as windfelled trees, or trees that are under severe physiological stress due to e.g. drought, root infection, crowding, age or defoliation. Alternatively, beetles can exhaust tree defences through mass-attacks coordinated by powerful aggregation pheromones (chemical signals) that rapidly direct hundreds of beetle attacks to a single tree. A tree can resist a certain number of attacks, but if the number exceeds this threshold the tree can no longer fend off the attackers. This ability to mass-attack trees is the key adaptation enabling outbreaking bark beetle species to kill healthy trees.
At the forest stand level the local beetle population can be either in the epidemic or outbreak phase (where the beetles can successfully colonize healthy trees) or in the endemic phase (where most trees resist attack and the beetles must breed in dead or severely weakened trees) (Fig. 3). Most of the time, tree resistance, stand structure, weather, competitors and natural enemies constrain populations at endemic levels (Raffa et al. 2008). However, widespread disturbances and climatic events can trigger outbreaks by reducing tree resistance and/or increasing beetle numbers. The supply of susceptible host trees is the key factor determining the ability of bark beetle populations to cross the epidemic threshold and switch from endemic to outbreak levels. Specific triggers of bark beetle outbreaks can 
be: extensive windthrows which can provide large amounts of undefended breeding material; severe drought or old age which can compromise tree resistance; warm weather which can reduce beetle overwintering mortality and hasten development; management practices which favour beetle reproduction; and immigration which can directly in crease beetle populations.

Although highly impactful and consequential, bark beetle outbreaks are actually intermittent events separated by lengthy endemic periods with low beetle populations. This pattern is true for all outbreaking bark beetle species. When the beetles cross the epidemic threshold they switch from focusing solely on weakened trees, which tend to support low brood production, to attacking healthy trees which tend to support higher brood production, thus releasing positive feedback. Outbreaks usually continue until the supply of suitable host trees is exhausted and the remaining trees are too small to support substantial brood production, or until populations are reduced by unfavourable environmental conditions such as low temperatures. Despite the long history of research on tree-killing bark beetles relatively little is known about how outbreaks actually collapse.

Disturbances are more likely to raise beetle populations above the epidemic threshold in homogenous stands, because large uniform stands favour a simultaneous population increase. In contrast, heterogeneous stands tend to show relatively minor population increases followed by subsequent declines, because the beetles exhaust the supply of susceptible trees with each successful attack. Additionally, disturbances that cause tree injury in a fashion that is spatially localized, such as wildfire, are unlikely to raise populations above the epidemic threshold, even in relatively homogeneous stands (Powell et al. 20I2). Finally, it is important to recognize that while many bark beetle species increase their numbers in response to environmental disturbances, most species do not transition to the self-generating dynamics of colonizing healthy trees, but rather have populations that rise and fall with the number of stressed trees supplied by the disturbance (Raffa et al. 2008). Therefore, the capability of a species to sustain lasting outbreaks in healthy stands should not be presumed without careful experimentation and analysis.

\subsection{Historical perspective}

During recent years, several fields of science have shed light on the historical role of bark beetle disturbances in various forest regions of the world. A dendrochronogical reconstruction of mountain pine beetle outbreaks in North America identified highly synchronous outbreaks of this species across large areas over previous centuries (Jarvis and Kulakowski 20I5). These extensive outbreaks played a role in forming natural landscapes and regional-level forest dynamics in the past. Reconstruction of disturbance regimes in Europe has also shown that montane spruce forests were historically shaped by infrequent, moderate- to high-severity natural disturbances caused by windstorms and bark beetle outbreaks (Čada et al. 2oI6). For example, the Bohemian Forest experienced at least five high-severity bark beetle outbreaks between I700 and I900. Similar evidence exists for mountain regions of the Carpathians. These findings imply that similar to other natural disturbances such as fire or wind, bark beetle outbreaks significantly influenced landscape-level forest dynamics, even at times when humans were not significantly altering natural disturbance regimes.

\subsection{Expected future development}

Disturbances from bark beetles have strongly increased in Europe in recent decades. Spruce and pine timber damaged by bark beetles increased by nearly $700 \%$ over the last four decades, from 2.I million $\mathrm{m}^{3}$ $\mathrm{yr}^{-\mathrm{I}}$ (I97I-I980) to I4.5 million $\mathrm{m}^{3} \mathrm{yr}^{-\mathrm{I}}$ (2002-2010) (Seidl et al. 20I4). This increase was caused in part by changes in forest structure and composition, as Europe's forests have been strongly altered by human land use over the last centuries. In addition to planting Norway spruce outside of its natural range, increased growing stocks and changed age-class distributions have contributed to making Europe's forests more prone to bark beetle disturbances. Overall, changes in forest structure and composition were responsible for approximately half of the observed increase in bark beetle disturbance over past decades (Seidl et al. 20II). The other half of the increase could be attributed to changes in climate and extreme weather events, and interactions between these different factors. The factors that have contributed to 
increasing bark beetle disturbances in the past will also operate in the future. Because forest structure only changes slowly, large areas of disturbance-prone Norway spruce forests still exist, and climate change is expected to continue over the coming decades. A further increase in disturbances from bark beetles in Europe is thus very likely. The timber damaged by bark beetles is expected to increase to 17.9 million $\mathrm{m}^{3}$ $\mathrm{yr}^{-1}$ by 202I-2030 in Europe (median over a wide variety of climatic and management scenarios). This puts the level of bark beetle disturbances expected for the near-term future above the range observed in the last 40 years.

Bark beetle disturbances are projected to increase all across temperate Europe in the future. The strongest relative short-term increase is expected in the Sub-Atlantic region of Europe, i.e. Germany, France, Denmark, the Netherlands, Belgium and Luxembourg. For this region, the average annual bark beetle damage projected for 202I-2030 is almost six times higher than what was observed from I97I-20I0 (Seidl et al. 20I4). These short-term trends are expected to continue throughout the $2 \mathrm{I}^{\text {st }}$ century. Simulations for Austria, for instance, indicate that even a moderate warming of $+2.4^{\circ} \mathrm{C}$ could lead to a three- to five-fold increase in the amount of timber damaged by bark beetles by the end of the $2 \mathrm{I}^{\text {st }}$ century, compared to the period I990-2004. This underlines that as the climate continues to warm, bark beetle outbreaks will increasingly also affect forests in which Norway spruce occurs naturally, such as the mountain forests of the Alps.

Beyond Central Europe, bark beetles will also increasingly be able to reach outbreak levels in Nordic countries. By the end of the century, Ips typographus will have switched from one to two generations per year in southern Sweden, Denmark, southern Finland and the Baltic countries (Jönsson et al. 20II). In general, areas and/or time periods that experience a combination of warmer and drier conditions will suffer most from increasing disturbances
(Sommerfeld et al. 20I8). Furthermore, increases will not happen at a consistent linear rate, but are expected to come in waves. These waves are likely to be synchronized across several hundreds of kilometres, and are triggered by climatic extremes such as cyclonic storm events and large-scale droughts (as in Central Europe in 20I8) (Senf and Seidl 20I8).

Climate change has a strong amplifying effect on bark beetle disturbances because (I) it facilitates bark beetle survival and development (e.g. through the completion of additional beetle generations per year), (2) it increases potential beetle habitat by allowing beetles to spread into higher altitudes and latitudes, (3) it increases the probability for extreme, region-wide weather events such as drought, which reduces tree defence, and (4) it facilitates tree killing because trees will be more susceptible to additional beetle generations that attack later in the summer. In addition to changing beetle population dynamics and host tree susceptibility, climate change also increases the risk of invasion by alien bark beetle species (see Box I).

The local impacts of increasing bark beetle pressure are, however, strongly modified by stand development. Areas that have been disturbed in recent years will not be strongly affected by beetles such as Ips typographus for decades, because the pool of large, potentially susceptible host trees is exhausted and young trees are not favourable for beetle reproduction. The suitability of trees for beetle reproduction increases as stands age, and forests that have last been disturbed in the $19^{\text {th }}$ century are now again highly susceptible to beetle attacks. In the long run, i.e. over centuries, climate change simulations show that bark beetle disturbances will decrease in the absence of management. This is because beetles will eventually exhaust their supply of suitable hosts, and mostly non-host broadleaved species will regenerate in response to climate warming, e.g. in areas such as Central Europe (Temperli et al. 20I3). 
Box 1. Invasive alien bark beetles

Given trends of globalization, forests in all parts of the world are increasingly being affected by many types of non-native organisms, including insects, tree pathogens, mammals and plants. With growing international trade, alien bark- and woodboring beetles have accidentally been introduced to regions outside of their native range via movement in wood and the wood packaging material that accompanies cargo. Though recent international agreements requiring phytosanitary treatment of wood in trade have provided some reductions in insect movement, these efforts have not been entirely successful and new introductions are anticipated to continue.

While the majority of non-native bark- and woodboring insects do not cause noticeable impacts in forests, a few of these species have caused massive levels of damage. Insects have long evolutionary histories of interacting with their host trees, which have evolved resistance such that in their native range, insects usually only colonize dead or dying trees. But when insects are introduced to new world regions, they may come in contact with host trees that are closely related to their native hosts but which lack evolved resistance. This phenomenon is well illustrated by the buprestid emerald ash borer, Agrilus planipennis. In its native range in Asia this beetle colonizes dying ash, Fraxinus spp., but in its invaded range in North America, none of the native ash species exhibit resistance and the beetle is currently killing most of these hosts. A similar phenomenon is seen in the invasion of North America by the ambrosia beetle Xyleborus glabratus; this species and its mutualistic fungal species Raffaelea lauricola are limited to colonization of dead tree material in their native range in southeast Asia, but in North America can successfully colonize and kill large numbers of healthy host trees in the laurel family.

For bark beetles, mutualistic interactions with fungi can be key to their successful host utilization, and invading populations sometimes develop novel associations with new fungal strains that increase the virulence of these insects. For example, in areas of China where the red turpentine beetle, Dendroctonus valens, has established, it has developed novel associations with fungi native to China and this relationship is a major cause of the massive tree mortality that this insect has caused there.

At least 18 species of non-native bark beetles have become established in Europe, with establishments apparently occurring at an accelerating rate (Kirkendall and Faccoli 2010). While none of these species have had catastrophic impacts, many of them are still expanding their ranges and it is thus probably too early to judge their ultimate impact. Furthermore, given that rates of new species establishments are continuing to accelerate, there is reason to be concerned about species that have not yet arrived or been discovered. For example, the polyphagous shot hole borer, Euwallacea sp., (native to Asia) has recently been discovered in both California and South Africa where it has caused extensive damage to European host trees and thus poses an obvious threat to European forests if introduced there. 


\section{Impacts of bark beetle outbreaks}

Bark beetles are important agents of natural forest dynamics, and have many impacts on forest ecosystems. These impacts are as variable as the spatial scale of disturbances by bark beetles, ranging from individual trees being killed to entire landscapes being disturbed.

\subsection{Impacts on ecosystems and biodiversity}

Bark beetle outbreaks reset forest succession, reduce primary productivity in the years following a disturbance, and strongly alter forest structure. Large-scale bark beetle outbreaks have substantial impacts on the biogeochemical cycles in forest ecosystems. They reduce carbon storage because carbon uptake is reduced after an outbreak due to reduced leaf area, and carbon losses from soils are increased due to higher soil temperatures and the increased activity of decomposers. The nitrogen cycle is also affected, since outbreaks increase nitrogen mineralization rates and improve the nitrogen supply to the foliage of regenerating trees. However, bark beetle outbreaks can also induce nitrogen losses from the system, e.g. in the form of nitrate leaching. The quantity of water fluxes also changes following bark beetle outbreaks. Due to reduced water use by trees, both water availability in the soil and water runoff increase after a beetle outbreak. The timing of water runoff can also change, as canopy interception is reduced and snowmelt is accelerated in beetle-disturbed forests.

In areas where the tree species composition has been strongly altered by past forest management, bark beetle outbreaks may facilitate the development of a more site-adapted species composition (Thom et al. 20I7). Bark beetle outbreaks can thus promote heterogeneity in forest landscapes. They increase light availability and the amount of dead wood at the stand level, which is beneficial for many forest-dwelling species. Consequently, many species, including some important red-listed species, respond positively to bark beetle disturbances (Beudert et al. 20I5). Recent analyses in the Bavarian Forest National Park - which has been strongly affected by bark beetle disturbances over the past 25 years - showed that the number of plant and animal species in disturbed forests equalled that in old-growth forests (Hilmers et al. 20I8). Bark-beetle disturbed forests also provide habitat for important flagship species of conservation, such as capercaillie (Tetrao urogallus) and hazel grouse (Tetrastes bonasia). Nonetheless, how bark beetle outbreaks will impact individual species strongly depends on the species' habitat requirements and life history strategy, with both positive and negative effects being reported in the literature. It is also important to note that the largely positive effects of bark beetle disturbances on biodiversity can be negated by salvage and sanitation logging activities for many species.

\subsection{Impacts on ecosystem services}

Functioning ecosystems contribute positively to human well-being through the ecosystem services they provide to society. Bark beetle outbreaks generally have a largely negative effect on ecosystem service provisioning, and thus human well-being. A global meta-analysis of disturbance effects on ecosystem services showed that all categories of ecosystem services, i.e. provisioning, regulating, cultural and supporting services, are predominately negatively impacted by bark beetle outbreaks (Thom and Seidl 20I6; Fig. 4).

The provisioning of timber is negatively affected by bark beetle outbreaks through: the need to harvest stands prematurely; a devaluation of the harvested timber by bluestain fungi; and elevated harvesting and regeneration costs, amongst other impacts. The changes in nitrogen cycling after disturbance, described above, can temporarily reduce water quality after bark beetle outbreaks at the local scale, while effects at larger scales and over longer time periods are minor (Beudert et al. 20I5). The climate regulating function of forests is negatively affected due to an increased carbon loss from disturbed forests. Increasing bark beetle disturbances are thus contributing to a warming climate by releasing carbon to the atmosphere, which - in turn - can result in higher levels of bark beetle disturbance. Furthermore, changes in the water balance of disturbed forests (i.e. reduced interception of precipitation and reduced transpiration) can lead to increased flooding and soil erosion following bark beetle outbreaks, although these effects are strongly modulated by local conditions and the disturbance management applied. 


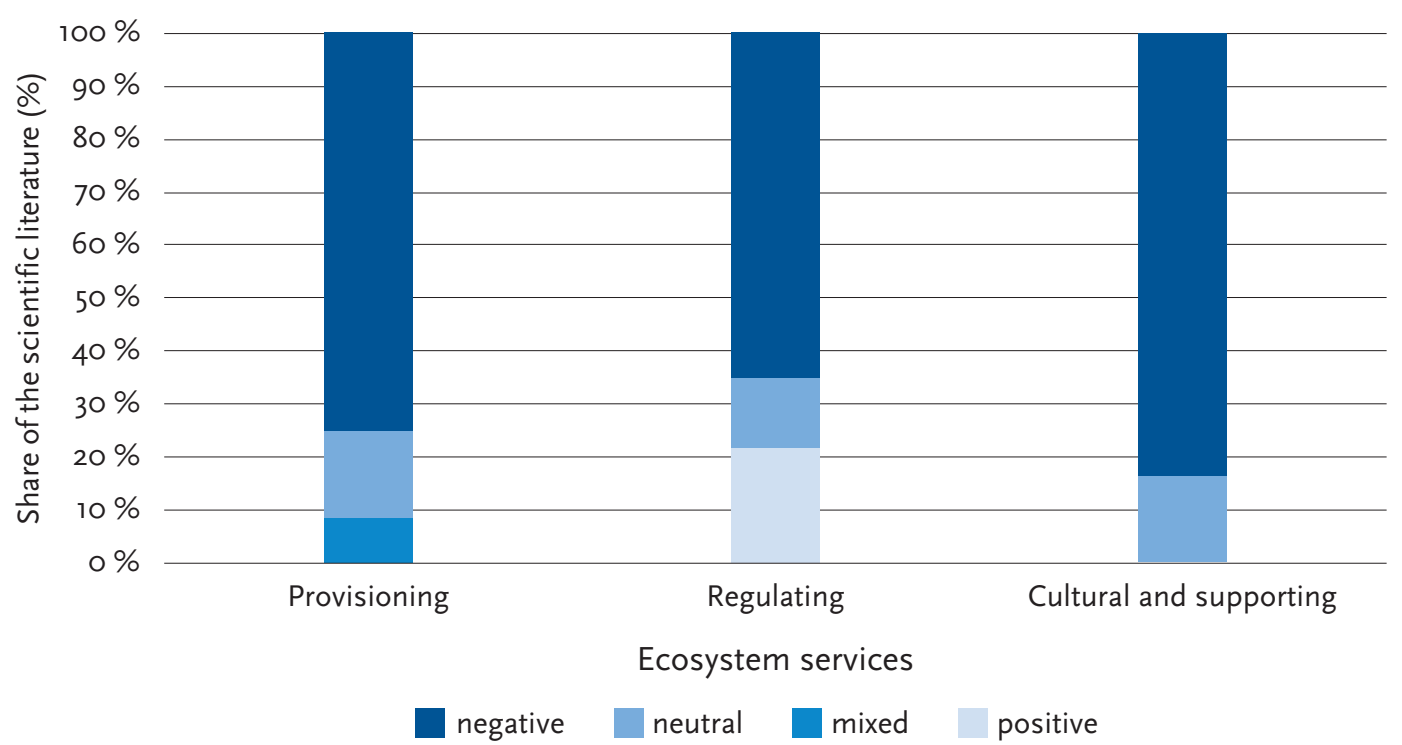

Figure 4. Impacts of bark beetle outbreaks on ecosystem services. The bars show the distribution of the evidence of bark beetle impacts (from positive to negative) on different ecosystem services collected from 41 scientific papers. Source: Thom and Seidl (2016).

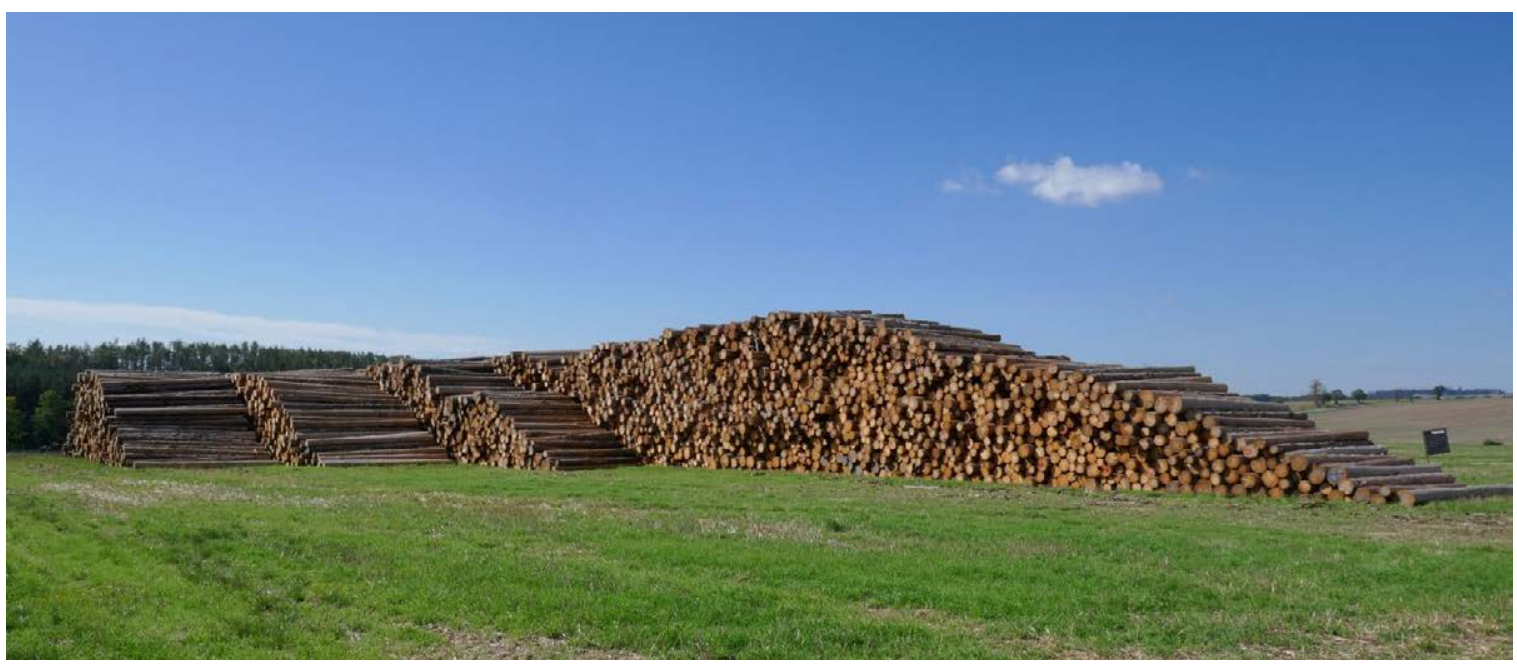

Figure 5. Salvaged timber which currently cannot be placed on the market because of the collapse in timber prices. Vicinity of bark beetle calamity area in the Czech Republic, Telč, 2018. Photo: Roman Modlinger.

\subsection{Economic impacts}

From an economic and business perspective, bark beetle outbreaks have significant implications all along the forest-related value chain. These implications concern both timber and non-timber economic values and vary greatly in their nature and intensity, from local and regional scales (including neighbourhood effects) to global and supranational scales (including international trade), and from short- to long-term effects. Bark beetle outbreaks may generate a complex pattern of economic losers but also winners. Because of this, there is widespread policy concern about reduced market stability and sustainability of forest-related activities after bark beetle outbreaks.

Most of the economic consequences of a bark beetle outbreak on timber markets are due to massive and synchronous salvage and sanitation harvesting behaviours. The aim of these operations is to create revenues for forest owners from beetle-killed timber before it is no longer merchantable. Following large outbreaks, logging infested trees and putting them on the market is almost the only way a forest owner 
can derive income from the disturbed forest, before the next rotation can be harvested 70-Ioo years later.

Salvage and sanitation harvesting gives an initial increase in timber supplies, sometimes encouraged by policy measures such as subsidies or regulated annual allowable harvest. This can lead to positive short-term market dynamics, including a temporary increase in employment and activity (logging, transportation, sawing, wood processing, etc.) and increased timber exports. However, markets may eventually become flooded with wood, as market participants increasingly attempt to liquidate beetle-killed as well as healthy timber, in anticipation of future outbreak spread or decreasing timber prices. Selling begets more selling and timber prices collapse (Holmes, I99I). For example, timber prices decreased in the Czech Republic in response to the massive outbreak in 2018, from $56-64$ euro per $\mathrm{m}^{3}$ (2OII-20I7) to I4-I6 euro per $\mathrm{m}^{3}$. Similarly, the storm Gudrun in 2005 and the subsequent bark beetle outbreak caused a temporary decrease in Swedish timber prices from 40 to 25 euro per $\mathrm{m}^{3}$, though the price recovered over the next few years (SFA 20IO) (see Chapter 5 for more details).

Large pulses of salvaged timber may also cause problems for the local sawmill industry, as supplies may exceed their processing capacity and cause timber storage issues with related supplementary costs and hazards. Timber export can also affect timber prices in more distant markets.

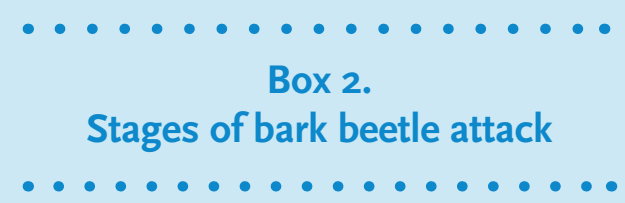

Green attack stage: an early phase of bark beetle attack in which trees do not show visual signs of infestation.

Red attack stage: a phase of needle discolouration which may last 1-2 years after the initial attack.

Grey attack stage: the needles have fallen from attacked trees to the forest floor.
After an outbreak, timber degradation and quality loss increase as the outbreak progresses from the green, to the red and grey attack stages. For example, bluestaining by beetle-associated fungi becomes visible two to nine months after attack. Even though bluestaining does not affect the structural integrity of the timber, it affects its visual appearance and makes the wood less desirable for consumers. As the timber continues to degrade and dry up, the wood structure is also weakened. Loeffler and Anderson (20I7) suggested that for a typical lodgepole pine (Pinus contorta) stand "the volume suitable for lumber declined by $15 \%$ between the green and red stages and declined by another 50\% between the red and grey stages". The authors also found that due to timber defects such as bluestaining, holes, resin pockets, rot and cracks the total cost of logging, loading, hauling and sawmilling increased by around $45 \%$ for each activity along the transition from green to red to grey attack stages.

In the short-term, timber-processing companies tend to benefit from the abundance of cheap timber generated by bark beetle outbreaks. However, timber producers, including those not directly affected by the disturbance, are negatively impacted due to reduced timber prices and increased logging, sanitation and regeneration costs. Thus, outbreaks have a negative net global short-term welfare effect on the forestry economy. For example, during the period I977-2004, the southern pine beetle (Dendroctonus frontalis) was estimated to cause a net short-term economic loss of about \$375 million (in 2004 constant dollars) to the timber market in the southern US. Timber producers lost about \$I.2 billion, while timber-processing companies gained about $\$ 837$ million from lower timber prices (Pye et al. 20II). Similar data for Europe are not available, but other North American studies conclude in the same direction.

In the longer-term, as forests regenerate after the disturbance, timber supplies and exports are expected to decline and timber prices to rise due to a reduced availability of timber on the market. This increase in timber prices typically does not compensate for the initial price decline, and, similar to the short-term impact, the long-term overall effect on the economic well-being of forest owners is negative (Pye et al. 20II; Bogdanski et al. 20II).

In addition to impacts on the private sector, bark beetle outbreaks and subsequent control measures also impact public budgets by increasing public 
spending and reducing tax incomes. A further effect for public entities may be a reduction in planned harvesting in state forest enterprises to reduce supplies and counteract a drop in timber prices.

The economic consequences of bark beetle outbreaks extend well beyond the timber market. For example, reduced carbon pools in forests following outbreaks can have negative economic impacts. If the forest carbon sink of an EU member country is reduced relative to its 'forest reference level', the EU's LULUCF policy states that it must be compensated by other mitigation efforts, which will have economic costs. In the future, forest owners may also be compensated for the ecosystem services their forests provide (Pohjola et al. 20I8), and since bark beetle outbreaks have large negative effects on ecosystem services such compensations may be reduced. Bark beetle outbreaks have also been found to decrease property values. For example, tree mortality caused by the mountain pine beetle in Colorado, USA induced a loss in home values of between 5.I\% and $22 \%$ depending on the county, timing and severity of the outbreak. At the same time, there was a general increase in home prices in areas not affected by beetle outbreaks (Cohen et al. 20I6).

Recreation values can also be negatively impacted by beetle attacks, but results in this regard remain ambiguous. For example, Rosenberger et al. (2013) reported that moderate to severe mountain pine beetle outbreaks in the Rocky Mountain National Park, USA can cause important losses in total recreation value. On the other hand, Dhar et al. (2016) found that overall visitation and revenue earnings were not affected by beetle outbreaks in Canadian national parks.

Given the many factors that affect market conditions and the diverse nature of bark beetle effects, our current approaches for a monetary valuation of global bark beetle impacts are limited. It is, however, clear that bark beetle outbreaks generate a complex pattern of losers and winners, at least in the short run. Small forest owners or companies and insufficiently diversified forest-dependent economies are most vulnerable to severe bark beetle outbreaks.

\subsection{Social impacts}

In addition to economic considerations, the reactions and actions of residents and other stakeholder groups are very relevant to the formulation of forestry policies. The major social impacts of forest disturbance by bark beetles are due to falling trees, aesthetic loss, reduced trail access, land use conflicts, loss of community identity, effects on park visitor experience, and emotions such as worry, fear or sadness. In addition to these negative impacts, some studies suggest that impacts such as emerging views with loss of trees and increased ecological awareness are viewed more positively by both local residents and visitors.

People's perceptions of and responses to environmental hazards are largely socially constructed processes and thus depend on how such issues are presented and contested. The power relations and institutional structures embedded within the issue of forest disturbance by bark beetles have direct implications for forest management. Recent bark beetle outbreaks and their management in protected areas in Europe have triggered paralysing political conflicts and social unrest. For example, Müller (2OII) showed how political conflicts over the management of beetle disturbance in Germany's Bavarian Forest National Park were rooted in opposite sociocultural understandings of the disturbed landscape by different groups. In Poland, efforts to control the beetle outbreak in the Białowieża Forest led to public demonstrations of disagreement with forestry policy, resulting in the involvement of EU authorities. Similar public engagement has been triggered by outbreak management measures in Slovakia and the Czech Republic. Most of these cases had some common denominators, such as diverging opinions about the role of natural disturbances in forests, contrasting understanding of the values of the post-disturbance landscapes, and a lack of suitable platforms to facilitate long-term discussions among the multiple stakeholders involved in disturbance management (e.g. forestry, environmental conservation, science, civic organisations, etc.).

Given the importance and scale of bark beetle outbreaks, there is surprisingly little research on their social consequences. For example, it is very difficult to find studies on this aspect in Europe (Müller 20II being a rare exception). In North America there have been some systematic studies of human responses to bark beetle disturbances (see studies cited in Qin et al. 20I5). Perceptions of beetle-related forest risks were found to be influenced by a range of factors including demographic characteristics (e.g. age, gender), residence status, previous emergency experience, perceived disturbance intensity, 


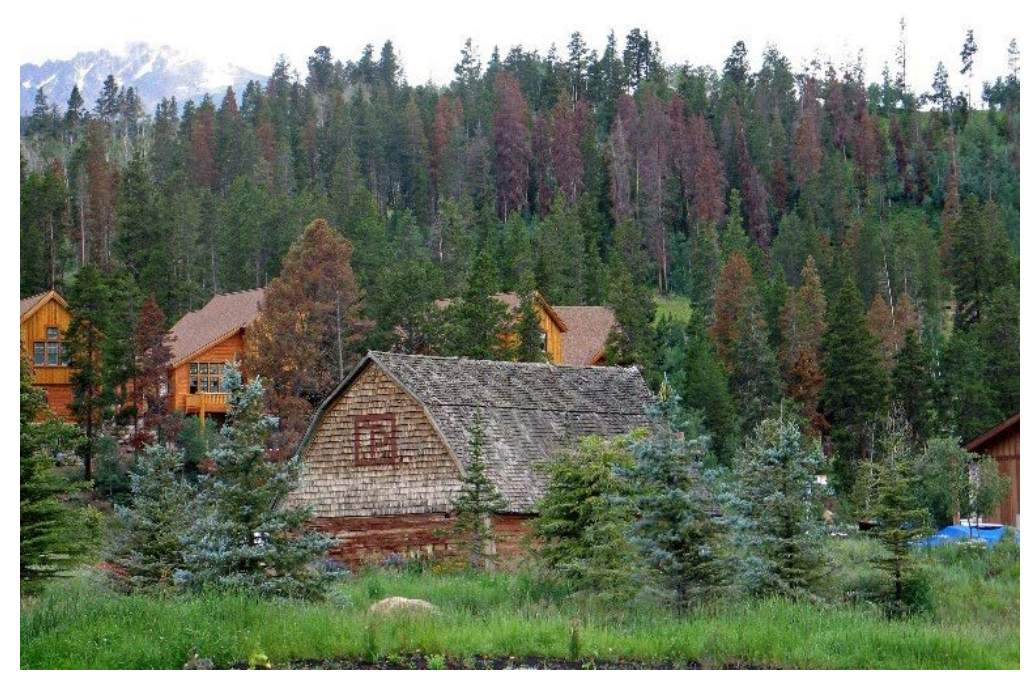

Figure 6. Pine mortality due to mountain pine beetles in the vicinity of human settlement in north-central Colorado, USA. Author: Courtney Flint. knowledge about beetle disturbances and relationship with land managers. People's perception of the risks posed by bark beetles generally increases with age, hazard experience, and being more informed about forest disturbances. By contrast, the relationships between risk perception, gender and satisfaction with (or trust in) forest management are rather mixed and unclear.

Other primary factors facilitating resident response to beetle disturbances include larger forest land ownership size, landowner preferences for wood production and/or for scenic/environmental reasons, low costs of prevention/mitigation, forest conservation concern, sources of information about forest issues, and the adoption of a forest management plan. Moreover, individual actions may also coalesce at broader scales such as the community or region. The most important factors promoting community activeness in response to beetle outbreaks are community emergency experience, participation in general community activities, and social networks and relations (Flint and Luloff 2007; Qin et al. 2015).

Different groups may perceive and respond to beetle outbreaks in distinct ways. Park visitors from local areas generally have a more negative view of beetle impacts than other tourists. Compared to longer-time residents, newcomers may perceive higher direct risks from beetles but lower levels of tree mortality. Newcomers also report lower satisfaction with land management entities, and are less likely to take action in response to forest disturbance.
As human response to beetle disturbance is directly influenced by the socioeconomic and biophysical characteristics of local communities (Parkins and MacKendrick 2007; Qin and Flint 2010), it is essential to maintain a good balance between diverse community contexts and landscape-scale forest management by incorporating local perspectives into risk mitigation strategies. Additionally, the social dimensions of forest disturbance by beetles vary between places experiencing different stages of beetle outbreaks. The various social aspects of bark beetle outbreaks are expected to evolve with changing forest landscapes and disturbance risks as well. For example, research on community response to spruce beetle (Dendroctonus rufipennis) disturbance on the Kenai Peninsula, Alaska showed that although the importance of beetle impacts generally decreased over time, concerns about immediate threats to personal property and safety (e.g. forest or grass fire) remained high, suggesting an evolving process much more complicated than usually assumed (Qin et al. 20I5).

In summary, bark beetle disturbances also involve the human dimension and have important social impacts. Despite this, there is still very little empirical research on these aspects in the European context. Clearly, in order to prepare better for future bark beetle outbreaks, it is essential to increase our knowledge on the social consequences and how to best manage them. More coordination among researchers in this emerging field is urgently needed in future endeavours, combined with innovative comparative analyses. 


\section{Outbreak management}

Effective outbreak management must begin with a clear articulation of the management objectives for the forest in question, i.e. what are the main intended values to be gained from the forest (economic, ecological, social). Here we outline outbreak management strategies for two contrasting management objectives of high relevance in Europe's forests. For the sake of simplicity, we refer to them as multifunctional and production forests (MFPF) and high conservation value forests (HCVF).

MFPF are forests where wood production is a key objective, though usually realized together with multiple other ecosystems services in Europe's forests. In these forests there are no or only a few legal restrictions on the management of bark beetle outbreaks.

HCVF are forests where the conservation of biodiversity, natural processes and other conservation values has a high priority. These forests frequently also provide important ecosystem services and/ or cultural identity to local communities. A more restricted range of management measures is available in these forests, which are designated by law or other instruments for conservation purposes, and include national parks, biological reserves and wilderness areas.

Obviously, many intermediate variants between these two categories can be found in forest management legislation and practice in Europe. It is important to realize that effective bark beetle management does not follow a generic blueprint. Rather, managers should select measures that are tailor-made for their local management objectives and conditions. To facilitate the development of local bark beetle management strategies we have compiled a comprehensive list of available management measures in the form of an outbreak management toolbox (Appendix A).

\subsection{Multifunctional and production forests}

\subsubsection{Reducing bark beetle outbreak risks}

A central component of forest management in Europe is to reduce the risks of damage due to disturbances, including bark beetle outbreaks. Employing effective risk reduction measures, however, generally requires a proper quantitative understanding of how management measures influence both the likelihood of a risk and the forest's susceptibility to this risk (Jactel et al. 2009). Too intensive risk reduction may, for example, generate overly vulnerable stands with high amounts of biomass that are susceptible to a diverse set of hazards. In these cases, the risk reduction measures actually lead to the opposite long-term effect of the one intended; a phenomenon known in wildfire management as the firefighting trap. There are indications that the same might apply for some attempts at long-term prevention of bark beetle outbreaks. Hence, it is not advisable to focus management measures entirely on risk reduction; rather risk prevention should be balanced with measures fostering forest resilience (section 4.I.3).

\section{Reducing rotation periods}

Forest vulnerability to various hazards is often age(or diameter-) dependent, with different disturbances affecting forests at different developmental stages. In particular, Ips typographus favours trees older than 60 years, or with a diameter at breast height larger than $20-25 \mathrm{~cm}$ (although they may also attack and reproduce in smaller and younger trees when their populations are very high). A similar relationship between stand age and vulnerability applies for wind disturbance, which can trigger or reinforce bark beetle outbreaks.

The rotation period in Norway spruce forests frequently exceeds roo years in many regions of Europe, resulting in large forest areas which are particularly prone to both wind and insect disturbances. For example, Hlásny et al. (20I7) found that in Slovakia Norway spruce had a less than $25 \%$ probability of reaching the age of Ioo years in the period I998-2009. Because of these vulnerabilities a shortening of the rotation period can be a powerful means to adapt forests to increasing bark beetle pressures. The optimal rotation period is, however, highly context-dependent and varies with site productivity, species mixture and silvicultural system. Therefore, specific recommendations on shortening current rotation periods need to be vetted in regional studies. Earlier harvesting might require the relaxation of forest legislation in countries which currently do not allow for sufficient flexibility in the rotation period. Reduced rotation periods also mean that harvesting operations will be more frequent, 
which may call for improved accessibility via an improved forest road network.

Reducing the rotation period may also have some undesired outcomes. It can, for instance, result in a temporary surplus of timber to the market with negative effects on timber prices, or it may reduce the supply of logs with larger dimensions. Shorter rotations may also result in a loss of habitat features that are important for biodiversity conservation and compromise supporting (water, soil nutrients) and cultural (aesthetics, cultural heritage) ecosystem services. Reduced forest carbon stocks due to shorter rotations may for example counteract efforts to mitigate climate change through carbon storage in forests. Therefore, shorter rotations should only be used following a clear articulation of local management objectives and a quantitative assessment of trade-offs between relevant ecosystem services.

\section{Reducing host tree availability and maintaining diverse stands}

Management that fosters tree species diversity has long been recognized as important for adapting forests to climate change, including the mitigation of disturbance impacts. Management for tree species diversity has received particular attention in secondary coniferous forests, although it might also increasingly be needed in native Norway spruce forests due to climate change.

An important argument for fostering more diverse forests is the insurance hypothesis. This states that diverse ecosystems are better buffered against disturbances than monocultures (have higher resistance) and recover more quickly (have higher resilience) (Jactel et al. 2009). Moreover, higher stand diversity is positively associated with the supply of many ecosystem services. Diverse forests are less susceptible to bark beetle infestation because they provide lower host tree availability, host larger populations of natural enemies and competitors, and have increased production of non-host volatiles that might deter the beetles (Semiochemical Diversity hypothesis; see page 25).

Griess et al. (2012) found that the probability for a pure Norway spruce stand to reach roo years under current climatic conditions in western Germany can be increased from $80 \%$ to $97 \%$ by increasing tree species diversity. The importance of fostering diverse stands further increases with climate change. Neuner et al. (20I4) found that the survival of pure 120-year-old Norway spruce stands decreased by $24 \%$ under unfavourable climate conditions, but that in mixed stands the decrease was only $7 \%$. Consequently, tree species diversity should be promoted, particularly in current Norway spruce monocultures planted outside their natural range, since such stands are at high risk of disturbance by bark beetles. For example, Marini et al. (20I2) found that forest disturbance in the European Alps was 7 times higher where spruce was planted in sites that were warmer than those within its historical climatic range. However, the importance of whether Norway spruce grows within or outside its native range is decreasing as climate conditions are changing rapidly. Climate change-driven bark beetle outbreaks threaten Norway spruce over virtually its entire range in Europe, and some recent outbreaks have, for instance, already reached native subalpine Norway spruce forests close to the timber line in the Alps.

Negative effects of off-site spruce planting might be partly offset by using suitable tree species mixtures and maintaining a suitable vertical and horizontal structure of stands, although aggravating climate change will increasingly compromise these opportunities. Still, spruce can probably be maintained outside its native range as an admixture species and its commercial (and other) use can be thus sustained. Simulation models can provide information on changing site suitability for spruce and other tree species under climate change and can be used to help managers select suitable tree species mixtures.

A conversion to mixed spruce forests can be accelerated if managers exploit the ongoing waves of bark beetle disturbances to create new and diverse stands. A practice that is increasingly applied is to add non-native species of high productivity, with soil amelioration effects or high drought tolerance to the species pools. An example is Douglas-fir (Pseudotsuga menziesii), which has already become the economically most important exotic tree species in Europe, and is increasingly discussed as an alternative in the conversion of secondary Norway spruce forests. However, aspects such as the vulnerability of exotic tree species to invasive pests (e.g. Dendroctonus pseudotsugae) and the possibility that native pests and pathogens will switch to exotic tree species need to be considered. A more detailed review of the possible impacts and prospects 
of using non-native tree species in European forests is, however, beyond the scope of this report (see e.g. Spiecker et al. 2019).

\section{Managing bark beetle population levels Sanitation felling}

Sanitation felling, which is the regular search for and removal of infested trees before the new beetle generation emerges, is one of the most widely used practices for bark beetle regulation in Europe. The practice is effective in reducing beetle densities and preventing population build-up mainly in non-epidemic conditions, and if a comprehensive search for infested trees is feasible. Under such conditions sanitation felling is not only reducing the number of beetles, but also interrupting the connectivity between local bark beetle populations (Seidl et al. 20I6).

Wermelinger (2004) formulated three rules which need to be followed to make sanitary felling efficient: (I) trees must be found and cut before the new beetle generation emerges; (2) the logs must be treated to kill the brood before logs are moved to collection yards, or the logs must be removed from the forest; and (3) if adult beetles are present in the bark they must be killed by burning or chipping the material. Under field conditions it is often difficult to implement all these components of sanitation felling properly. There are several options that may increase the efficiency of sanitation felling in the current context of intensifying bark beetle outbreaks:

Detection of newly infested trees is a critical element in sanitation felling. It is typically based on visual surveys by forestry personnel, who identify infested trees e.g. by boring dust from beetles entering the stem. Visual surveys are, however, very time consuming and detection rates are highly variable. A promising way to increase detection efficiency is to use remote sensing technologies, including high-resolution spectral images from cameras installed on drones, combined with (semi)automated image processing. Recent research indicates that such approaches can detect infested trees already in the 'green attack stage' when they do not yet show any needle discolouration (Abdullah et al. 20I8). The limiting factors for the widespread application of this technology in practical forestry are the lack of skills to operate drones and interpret images, and current legislation in many countries that restricts the operation of drones in the field. In addition,

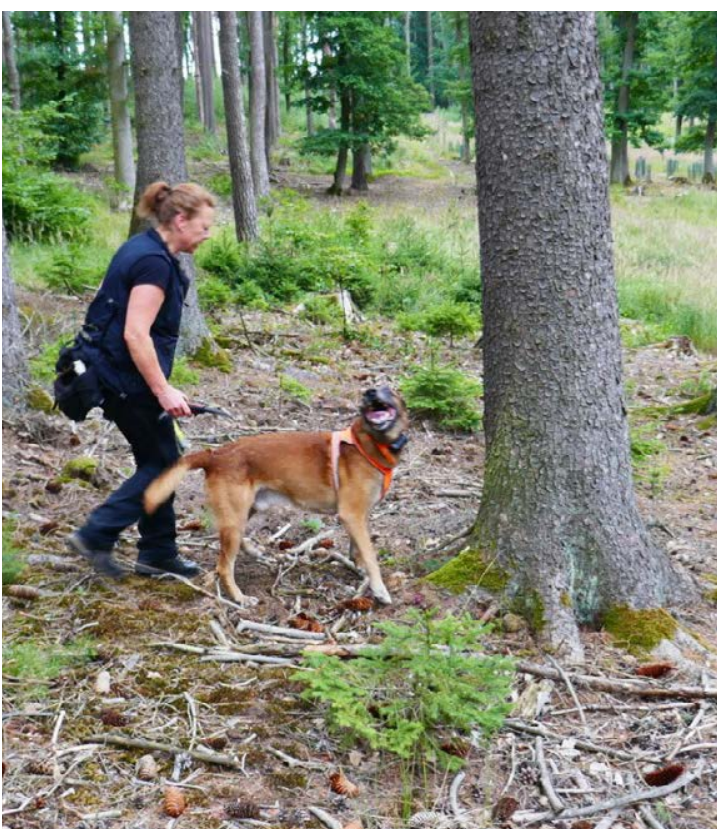

Figure 7. Experimental use of a sniffer dog to detect trees infested by bark beetles in the Czech Republic, Stríbrná Skalice, 2018. Dog handler is Annette Johanson. Photo: Roman Modlinger.

drones can only cover relatively small areas. A promising tool for large-scale operations is the use of new high-resolution satellites such as Sentinel 2. In future we expect to see a rapid development of remote sensing-based early detection technologies for user-friendly and cost-efficient applications in forestry.

Experiments have shown that sniffer dogs can be trained to recognize pheromone blends from both early and late stages of bark beetle attack, and track the odour source to the infested tree. In contrast to humans who rely on visual cues, dogs may detect infested trees at a distance of up to $150 \mathrm{~m}$. Sniffer dogs cannot be used across large spatial scales, but can provide support for early detection in special circumstances.

In sanitation felling it is important that if the trees cannot be removed before the brood exits, beetles must be prevented from leaving the felled trees and infesting surrounding trees. Bark removal (debarking) and subsequent bark chipping or burning are proven methods which kill most of the beetles. The methods are, however, labour-intensive and require specialized tools. Recently, so-called bark-scratching has been developed as an efficient and less labour-intensive alternative to debarking. Thorn et al. (20I6) found a $96 \%$ reduction in the number of 


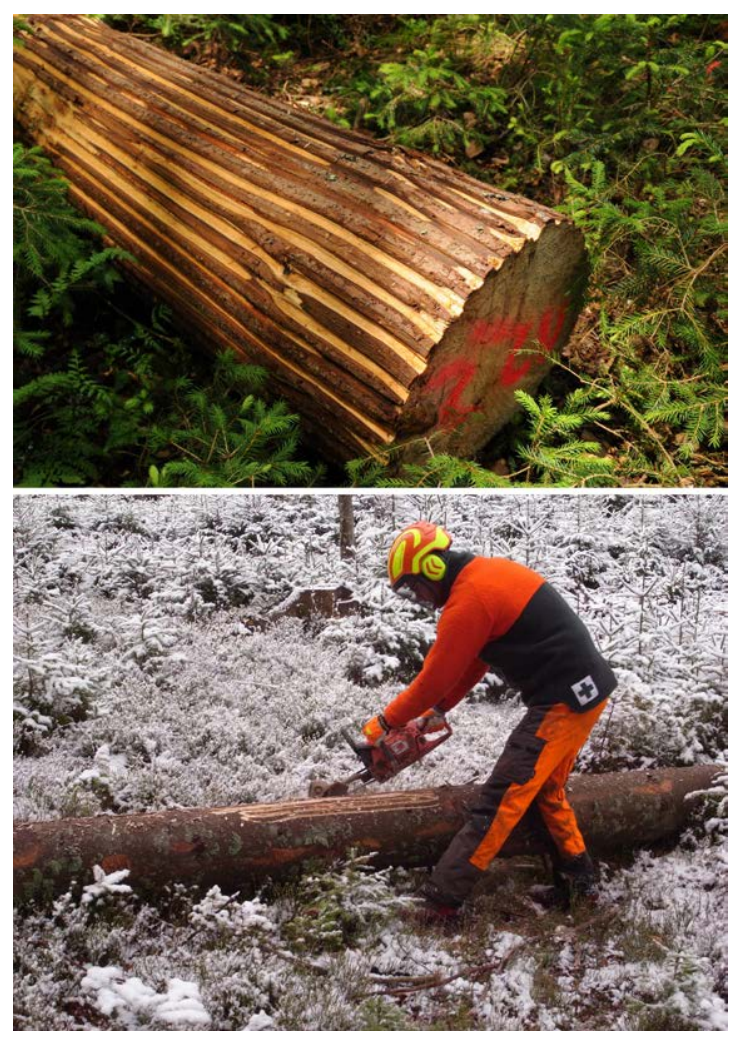

Figure 8. Bark scratching in the Bavarian Forest $\mathrm{Na}$ tional Park, Germany. Photos: Jörg Müller.

emerging beetles using debarking and an $89 \%$ reduction using bark scratching, compared to untreated control trees. Bark scratching has little impact on deadwood biodiversity, is more attractive than debarking for visitors, and is cheaper when done with a recently developed device (Hagge et al. 20I8). Here the impact was shown even for already infested trees. However, the efficacy of this within-tree procedure in stand- and landscape-level protection is contingent on the efficacy of detection of infested trees and their extraction.

Fumigation, i.e. the application of gaseous insecticides, is another option for preventing beetle emergence from infested logs. Treated logs are covered with a tarpaulin and exposed to the gas for an extended period of time. The pesticide methyl bromide which was originally used for this purpose has been banned in Europe for environmental and human health reasons. Ethanedinitrile is an alternative fumigant which has recently received increased attention in several countries. Fumigation is reported to be less labour-intensive than debarking or bark-scratching, but the method requires further testing. Other chemical approaches to prevent beetle emergence from infested logs are to spray insecticides directly on the logs or to cover logs with insecticide-treated nets. However, the application of insecticides may have negative environmental effects and interfere with independent third-party certification of sustainable forestry, such as FSC and PEFC.

Removing trees damaged by wind, snow and ice Because windthrows and other abiotic disturbances may trigger and reinforce bark beetle outbreaks, disturbed areas should be managed properly to reduce outbreak risks. Fresh windthrows are an attractive breeding substrate for bark beetles, and are preferred over healthy trees because of their greatly reduced defences. Depending on local conditions, such as temperature and prevalence of uprootings and stem breakages, trees damaged by wind can be used by bark beetles for one or two seasons after the windthrow. Initially, large windthrows thus attract many beetles from the surrounding areas and act as a beetle sink. When the breeding resources are exhausted, however, the much enlarged beetle population leaves the windfelled area and may colonize surrounding standing trees. The build-up of beetle populations in windfalls occurs much more rapidly in areas with two or more beetle generations per summer than in areas with univoltine beetle populations. Large-scale windthrows can apparently increase beetle populations above the epidemic threshold and trigger outbreaks even in the absence of climatic triggers (Marini et al. 20I7). Climatic outbreak triggers are more important when the amount of windfelled trees is limited. There are also indications that the scattered windthrown pattern is more conducive to bark beetle outbreaks than largescale concentrated damage (Potterf and Bone 20I7).

To prevent population build-up, it is recommended that windfelled trees are removed before the beetles begin to fly in the spring, or before the first new beetle generation emerges. If the windfelled areas are relatively small and close together, and logging is done in a timely and efficient manner, the risk of outbreak initiation or expansion can be reduced. Cleared areas also facilitate silvicultural follow-up activities such as planting and regeneration protection. Hazard rating models can be used to identify priority areas for tree removal, for example depending on beetle numbers in surrounding stands or storm gap size. 
Still, there are concerns about the efficacy of tree removal following large-scale windthrows, and/ or when bark beetle populations are already high. In such cases, early and intensive removal of windfelled trees can be hampered by logistics problems, while collateral impacts can be severe. Loggingrelated disturbance may for example imperil ecosystem recovery, negatively affect biodiversity and ecosystem services (Leverkus et al. 2018), and compromise ecological resilience mechanisms. The removal of snags and fallen logs might reduce population levels of numerous bark beetle predators that use such trees as habitat (although the importance of predators in outbreak regulation and the effect of tree removal on predator communities are not sufficiently understood). Another negative effect of windfall removal is that harvesting machines can reduce regeneration success via soil compaction, which increases seedling water stress. A positive effect of leaving windfelled trees in the forest is that they represent an important biological legacy, and retaining them can positively affect natural stand recovery, soil properties, nutrient inputs and landscape heterogeneity.

Current science cannot provide an unambiguous answer as to whether windfelled trees should be removed or not. Nonetheless it is clear that due to the complexity of the decision much deeper considerations of trade-offs between outbreak prevention and collateral impacts are required than are currently practiced.

\section{Trapping beetles}

In addition to sanitation felling and removal of mechanically damaged trees, various trapping methods have been used extensively in bark beetle management. The rationale for using traps is either to monitor beetle populations, including the potential emergence of invasive species, or to reduce beetle numbers by mass-trapping and thereby prevent attacks on living trees.

Trapping techniques include the use of traps baited either with species-specific pheromones or host compounds that may attract a variety of woodboring insects. A related strategy involves the use of pheromones to attract beetles to trap trees or log traps; once attracted, beetles can either be killed with pesticides or removed by harvesting the logs. To date, there is little scientific evidence that trapping either with pheromone-baited traps or trap trees is effective

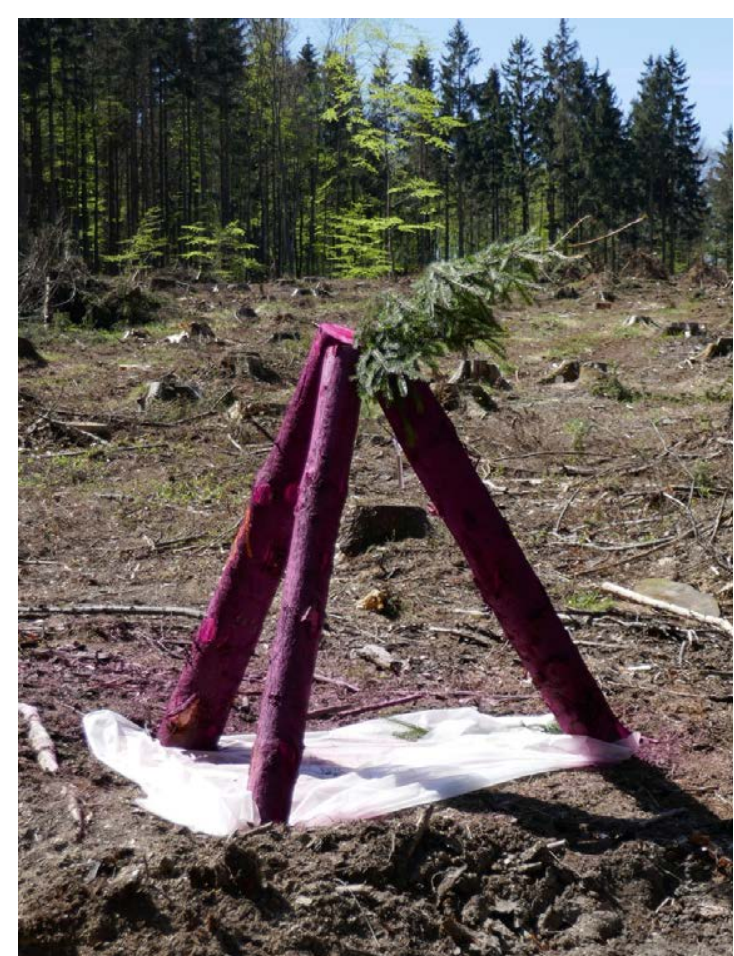

Figure 9. Pheromone-baited and poisoned log tripod used to trap bark beetles, Czech Republic, Libavá, 2018. Photo: Roman Modlinger.

at reducing beetle populations or the number of attacked trees. As for many other sanitation measures, research on the efficacy of trapping techniques in reducing outbreak risks and damage rate is generally lacking, particularly for large-scale applications. Often, the efficacy of trapping is overestimated and the cost of the traps is neglected. Pheromone traps usually capture only 3-10\% of beetle populations at a relatively high cost, with substantially larger capture rates for trap trees (Wermelinger 2004). Due to the poor cost/benefit ratio, the use of pheromone traps for mass-trapping has been abandoned in Scandinavia and most parts of Germany and France, where pheromone traps are currently only used for research and monitoring purposes.

Future developments in the trapping of bark beetles include smart traps which might use machine-learning algorithms to differentiate between target and non-target insect species, evaluate temporal patterns of captures, or inform about the abundance and phenology of co-occuring insect communities such as natural enemies. Still, the main use of such traps will continue to be improved monitoring and early warning, rather than population reduction 
and outbreak suppression. Other upcoming innovations may include autonomous trapping systems with automatic data transfer to a control centre, thus reducing maintenance costs and making trapping data available in near real-time.

\section{Managing the landscape configuration to prevent beetle spread}

The connectedness of host tree and beetle populations at the landscape scale is increasingly recognized as an important determinant of bark beetle infestation risk (Seidl et al. 20I6). However, traditional bark beetle management has largely focused at the stand scale, neglecting landscape-level factors. An important new management strategy might be to more deliberately aim to reduce risks by managing the landscape configuration. Specifically, trapping and sanitation efforts should be focused on infested stands that may act as hubs within the bark beetle population because they are spatially well connected with other beetle spots on the landscape.

Furthermore, high risk areas dominated by mature Norway spruce forests should be separated from each other by buffer stands with low habitat suitability for bark beetles, such as stands dominated by non-host trees. These buffers can be thought of as an analogy to strategic fire breaks in fireprone landscapes. Buffer stands, however, must probably be several hundred metres wide to be effective. Kautz et al. (2OII), for instance, found that $65 \%$ of new Ips typographus infestations occurred within a Ioo $\mathrm{m}$ radius of the previous year's infestations, and $95 \%$ of new infestations remained within $500 \mathrm{~m}$.

If done correctly, an improved landscape configuration could reduce the likelihood that individual bark beetle infestation spots will spread to neighbouring stands. This could reduce the risk that large-scale outbreaks will develop, even though the positive effects might take several decades to materialize. Forest ownership structure is obviously a crucial factor hindering efforts to create more resilient landscapes with a reduced risk for bark beetle outbreaks. To promote this approach, the benefits of landscape-scale management of bark beetles needs to be communicated effectively to forest owners and other stakeholders. This might require the establishment of platforms to actively facilitate this communication and coordination.

\section{Quarantine measures against alien pests}

Like elsewhere in the world, non-native bark- and woodboring insects continue to be introduced to Europe, and their establishment and spread presents a serious risk to European forests (see Box I). Several measures are available to reduce this risk. Solid wood packaging materials (e.g. pallets) that accompany cargo in trade are a major introduction pathway, and measures that minimize the arrival of infested packaging material are a primary tool for preventing invasions. In 2005, the International Plant Protection Convention implemented International Standards for Phytosanitary Measures No. I5 (ISPM I5), requiring that all wood packaging material that is moved between countries must be either heat-treated or fumigated. The implementation of ISPM I5 has reduced contamination levels in wood packaging materials and the risk of new introductions, but it has not eliminated the risk entirely. In addition, European countries have relatively weak regulations for the import of live plants, another important introduction pathway for bark- and woodboring insects. The risk of introducing new damaging bark beetles could be reduced by implementing more rigid regulation of solid wood packaging materials and import of live plants.

When prevention of an initial introduction fails, newly invaded populations may be eradicated if they are detected during the early stages of establishment. Consequently, many European countries conduct early detection surveillance programmes targeting alien bark- and woodboring insects. These programmes typically use traps baited with either host attractants or specialized pheromones. Today, there is no comprehensive network of surveillance traps across Europe, and the establishment of such a network would provide opportunities for early detection and eradication of new invasions.

Once new bark- and woodboring insects have become established in a new territory they typically expand their range via movement of infected wood packaging material or logs, lumber or fuelwood. The establishment of quarantine treatment of such products (e.g. heat treatment) or quarantine zones that limit their movement within Europe would reduce the spread of bark- and woodboring pests within the continent.

A number of different measures to reduce the potential spread of alien pests and pathogens have been proposed, including the sharing of costs 
generated by invasions among the main stakeholders (e.g. Hantula et al. 20I4). The latter measure, however, would probably be opposed by importers and other parties as violating the Agreement of Sanitary and Phytosanitary measures (SPS) and other conventions. We generally recommend focusing on improved biosecurity measures in Europe in a way that embraces SPS and the International Plant Protection Convention, which currently lags behind other developed regions.

\section{Other measures}

Other measures to reduce the risk of bark beetle outbreaks may be used under certain local conditions or management objectives. This may include, for example, improving tree vigour via thinning operations (primarily as an outbreak prevention rather than outbreak treatment tactic), promoting a number of natural enemies of bark beetles, using biological insecticides such as Beauveria basiana, and using anti-aggregant lures or glue traps. These measures can be included in integrated outbreak management systems tailored to specific conditions, while honouring the general principles of outbreak management outlined in this report.

Entirely new approaches to bark beetle control can be based on methods from functional genomics. RNA interference (RNAi) is a rapidly evolving technology for pest control, which, unlike most other pest management methods, is highly species-specific (though its efficiency varies significantly among insects). Interestingly, the method seems to perform reasonably well against beetles (Yoon et al. 20I8). Hence, the use of RNAi-based insecticides - while not yet operationally available - is a promising prospect for bark beetle management in the future. Further research is required on aspects such as the effects on non-target species, the persistence of the insecticide in the environment, the potential for resistance development, methods for indus trial-scale production and appropriate systems for mass-application.

Another future option for bark beetle management could be the application of the Semiochemical Diversity hypothesis, where host location is disturbed by non-host odour anti-attractants (Zhang and Schlyter 2003). Blends of the anti-attractants are available in synthetic form identical to those from leaves and bark of non-host trees. Consistently high dampening effects of artificially increased semiochemical diversity were found by experimental application of anti-attractant blends in both $I$. ty pographus and $D$. ponderosae. The increase of natural semiochemical diversity is likely to be a contributing factor to the increased resilience of mixed conifer-broadleaf forests during outbreaks (Kärvemo et al. 20I6).

\subsubsection{Responding to bark beetle outbreaks}

Bark beetle outbreaks in production forests usually trigger numerous actions that aim to prevent further outbreak expansion and mitigate economic and social impacts. In most cases the earlier described sanitation felling is accompanied by salvage logging, which primarily attempts to recoup economic losses from beetle-killed timber. The effects of sanitation and salvage logging may obviously be complementary, since infested timber removed for sanitation purposes can be sold, and timber extracted to recoup economic losses will reduce the amount of available breeding substrate. However, the main motivation of the two measures is different.

Salvage logging has long been recognized as a key component of post-disturbance forest management. The economic motivation for salvage logging, to prevent wood degradation and trade damaged timber at reduced prices, is definitively legitimate in commercial forests with an emphasis on wood production. In fact, when Müller et al. (20I8) reviewed 42 cases from all continents they found that the primary argument for salvage logging both in protected and unprotected forests was to access the timber before the wood quality deteriorated.

The economic profitability of salvage operations, however, differs between countries and over time. Profitability clearly depends on how fast the timber can be salvaged, because timber quality deteriorates as bark and ambrosia beetles colonize the trees and infect them with bluestain fungi. Salvage logging can be profitable when timber markets are good and timber prices are not reduced by a large supply of salvaged timber. In general, salvaging of beetle-infested trees tends to be more profitable than salvaging of structurally damaged windfelled trees. The economy of salvaging can be affected by the options and capacities for temporary storage of salvaged timber. Improving the capacity and methods for timber storage (such as 'wet storage') are important components of preparedness for intensified forest disturbances. 


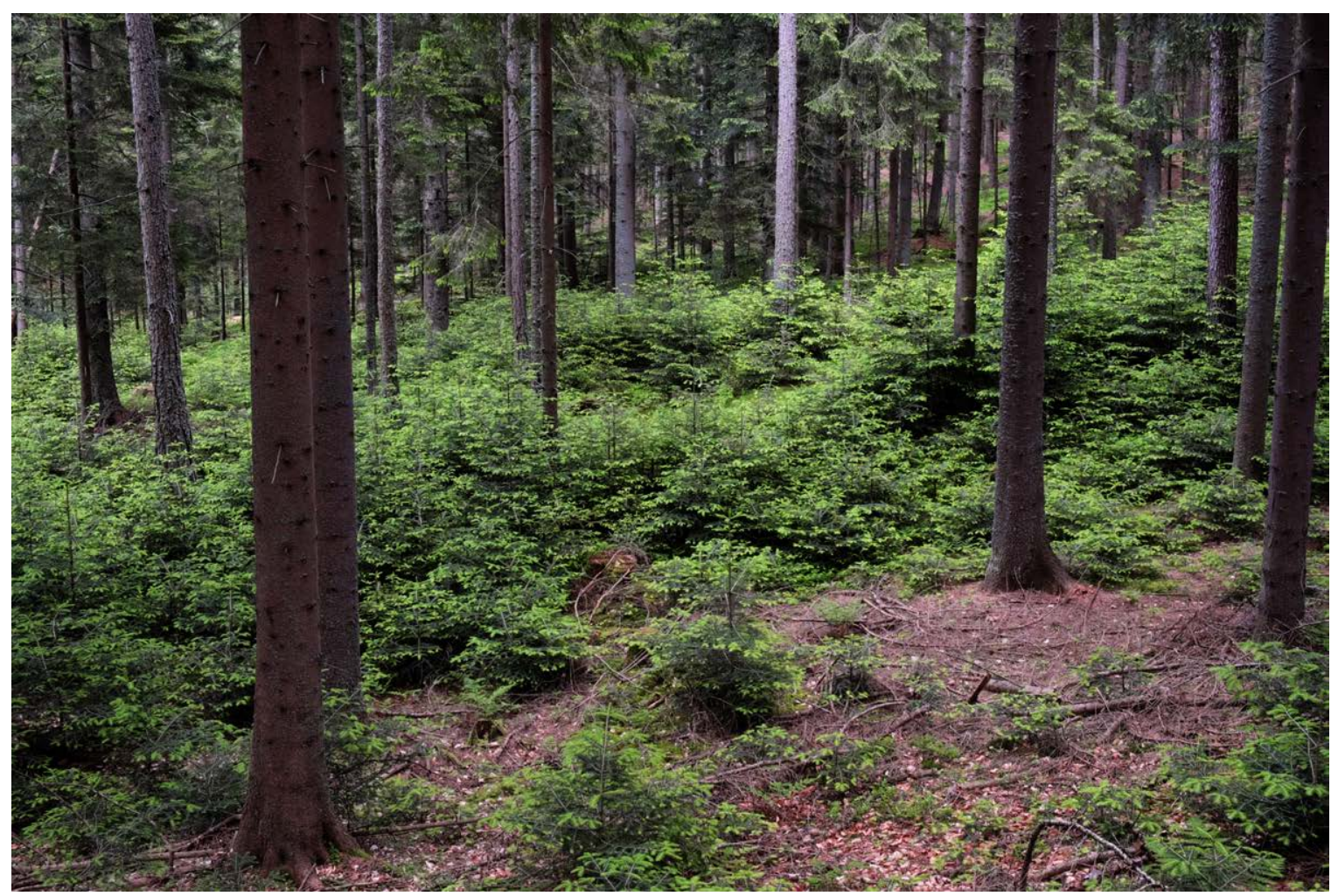

Figure 10. Layer of advanced regeneration in spruce forest, Austria. Photo: Rupert Seidl.

Under some conditions salvaging costs might be higher than the value of the extracted timber. This is particularly relevant for the situation in Central Europe today, where a dramatic reduction in spruce timber prices and limited capacities for timber storage are questioning the economy of salvaging. Also, low value stands with a positive outlook for natural regeneration may generate greater stand value when left unsalvaged. Hence, leaving beetle-killed trees unsalvaged in the forest must be considered as a viable management option, particularly when the beetles have left and the trees are no longer an active source of beetles. Abandoning salvaging may also free up resources that can be used in a more efficient manner.

Leaving unsalvaged trees in the forest generates concerns about wildfire risks and threats to infrastructure and human safety from falling trees. Salvaging might, for example, reduce fuel load and disrupt its horizontal and vertical continuity. While salvaging with the intention to protect energy infrastructure, roads and buildings can be thought of as an unquestionable priority in disturbance management, more research is needed to provide unambiguous answers about the risk of wildfires after bark beetle outbreaks. To date most of available evidence suggests that bark beetle outbreaks do not substantially modify the fire risk. Instead crown fires seem to be primarily contingent on the incidence of dry conditions (Black et al. 20I3; Simard et al. 20II).

Changing logging regimes have also triggered controversies between different stakeholders about the main motivations for logging and other unaccounted effects. Concerns emerge, for example, that logging may affect cultural, regulating and supporting ecosystem services (Leverkus et al. 20I8). Similar to sanitation logging, the use of salvage logging requires more complex considerations of the economy of harvesting and potential side effects than are typically practiced.

\subsubsection{Fostering resilience}

Resilience is the ability of an ecosystem to maintain its functions in the face of disturbance (Holling, I973). Important indicators of resilience are a swift recovery from disturbance, and a return to a state that is functionally equivalent to the one before the disturbance. This characteristic of forests is increasingly discussed in science and policy, as it becomes more and more clear that avoiding disturbances 


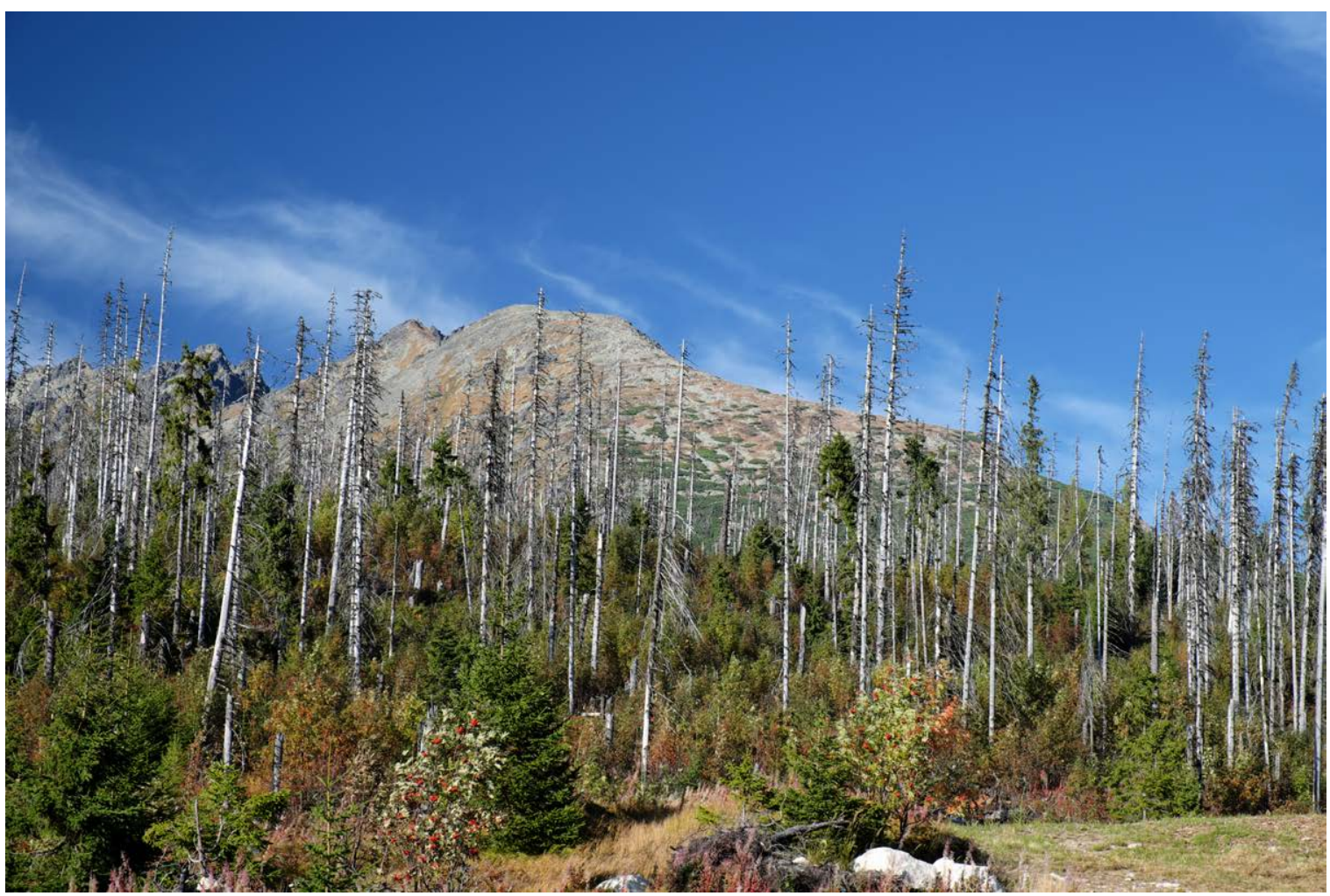

Figure 11. Disturbance legacies, High Tatras, Slovakia. Photo: Rupert Seidl.

completely is neither possible nor desirable. Forests are remarkably resilient ecosystems.

This resilience comes from the fact that trees have co-evolved - and adapted to live - with disturbances over millions of years. Trees affected by drought (an important predisposing factor for bark beetle outbreaks) can, for instance, recover their growth quickly in the years following a dry spell, an ability called engineering resilience. At the ecosystem level, the ability to recover from disturbance is referred to as ecological resilience. If a severe and large-scale disturbance causes a system to fundamentally change (e.g. regeneration failure following disturbance, and subsequent conversion from a closed-canopy forest to an open savanna-type ecosystem), the ecological resilience of the system is exceeded. An example of such a fundamental change can be found in the Mediterranean ecosystems of Europe, which used to be dominated by holm oak (Quercus ilex), but changed to shrubland ecosystems (called macchia or maquis) after excessive disturbance from human land-use (Henne et al. 20I5). It is important to note that once the ecological resilience of a system is exceeded, a tipping point is reached and subsequent transition to a different system can unfold abruptly.
The resilience concept is not only limited to describing ecological stability but can also be extended to the social realm. As a natural analogy of ecological resilience, social resilience refers to the ability of groups or communities to cope with external biophysical, social and economic disturbances without significant upheaval. In managed forests, for instance, we are frequently concerned about continuously providing ecosystem services to society despite the occurrence of natural disturbances (Seidl et al. 20I6).

\section{What makes a forest resilient?}

In Europe, forests have proven to be highly ecologically resilient to recent bark beetle outbreaks. In the Bavarian Forest National Park, for instance, which has seen one of the most severe and extensive bark beetle outbreaks recorded in Central Europe in decades, the average stem numbers I5 years after the outbreak were $2000 \mathrm{~N} \mathrm{ha}^{-\mathrm{I}}$ (Zeppenfeld et al. 20I5). Recovery was faster in adjacent managed forests, but also required a considerable amount of resources (e.g. for planting). Without any human intervention the ecological resilience of the system also resulted in a full recovery to stem densities equalling 
planting targets in managed forests. Understanding the drivers of resilience is an active field of research, and science does not yet fully understand all the processes that lead to recovery after disturbance, or cause an ecosystem to change states abruptly. However, some key factors contributing to the resilience of forests have already been identified:

Interactions across spatial scales: stands disturbed by bark beetles frequently regenerate via seeds that come from surrounding undisturbed stands. This means that the spatial context of a disturbed stand can greatly enhance the ability of the forest to recover, e.g. if the distance to the next seed source is small.

Biological legacies: this term summarizes all the biological elements of the ecosystem before the disturbance that are carried over to the state after the disturbance, thus constituting a form of ecological memory of the system. Biological legacies include seed banks, live trees not affected by bark beetles (such as advanced regeneration), dead trees serving as nurse logs, and mycorrhiza facilitating the growth of the recovering tree cohort.
Response diversity (Mori et al. 2013): this means that different trees in a forest react differently to a disturbance, and in doing so enhance the ability of the ecosystem to recover. If the stands surrounding an area disturbed by bark beetles are diverse and contain not only late-successional species (with relatively low seed dispersal distances) but also early-successional species (with the ability to disperse over long distances), the recolonization of a disturbance patch will happen at a considerably faster pace.

\section{How can we strengthen resilience in management?} Resilience-based management is often fundamentally different from approaches aiming for risk reduction. While the latter aim to prevent disturbances, resilience thinking acknowledges that disturbances are a natural part of ecosystem dynamics that cannot be completely controlled (Holling and Meffe, 1996). The prevention of natural disturbances is in conflict with natural ecosystem dynamics (and thus not consistent with ecosystem-based or close-to-nature management). Furthermore,

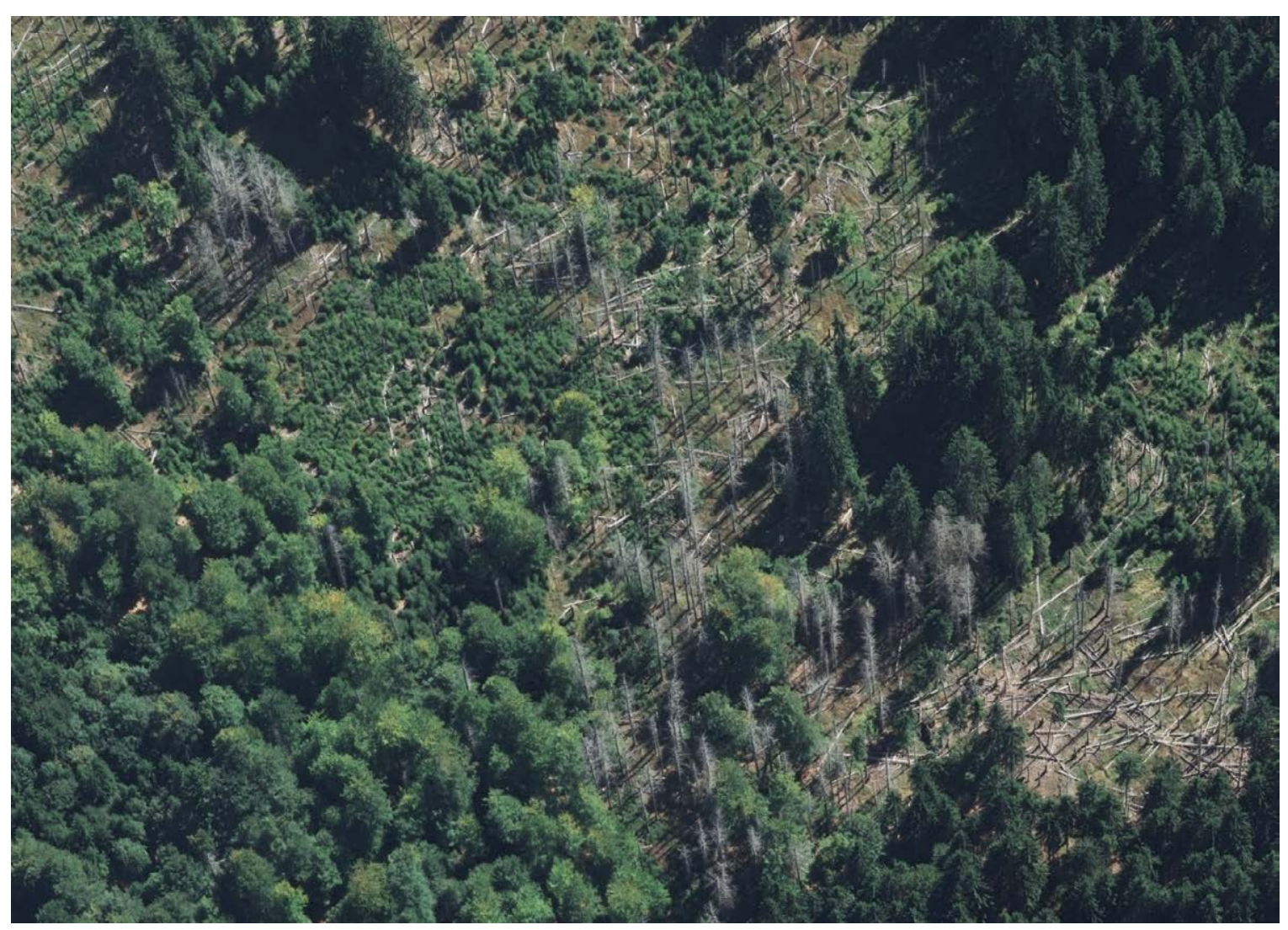

Figure 12. Aerial photo of a spruce forest with a high structural diversity in the Bavarian Forest National Park, Germany. Author: Jörg Müller. 
preventing small disturbance events can increase the propensity for very large events in the future. An alternative perspective is to conceive natural disturbances as opportunities to adapt forests to rapidly changing environmental conditions. Embracing the structural and compositional diversity created by natural disturbances (rather than aiming to 'correct' it via post-disturbance management) can make ecosystems more robust to future disturbance. Such a different perspective on natural disturbances can complement classical forest protection approaches, in that protection focuses on assets of high value in the landscape for which risks can be reduced efficiently, while resilience is fostered and natural disturbances are embraced in other parts of the landscape (Seidl, 20I4).

Specific management measures fostering resilience include:

- The promotion of mixed species forests containing both early- and late-successional species. Such mixtures recover considerably faster from disturbances than other ecosystems, due to their elevated response diversity.

- Facilitating structurally diverse stands. If the overstory is lost to bark beetle attack the understory can immediately utilize the increasingly available resources such as light, water, and nutrients, and take over important forest functions. Maintaining a layer of advanced regeneration in the understory is also an efficient means to increase the speed of recovery after disturbance. Furthermore, fostering high structural diversity in the landscape will limit the spread of bark beetles. It also ensures that mature stands serving as seed sources can be found in close proximity to disturbed patches, fostering recovery via natural regeneration.

- Retaining biological legacies wherever possible. This entails leaving surviving live trees on site, and not completely salvaging deadwood after disturbances.

- Keeping nursery capacities at levels that allow speedy replanting of large disturbed patches with desired future species.

- If needed, ungulate densities may be regulated to levels where they do not hamper a successful regeneration of desired tree species.

Managing for resilience against bark beetles has the advantage that many of the measures above are also efficient against other disturbances (e.g. wind, other insect pests). As we cannot know with certainty which disturbances will affect our forests in the future, fostering resilience is a potent means for dealing with uncertainty in management (Seidl, 20I4).

Finally, measures that foster the capacity of social response to disturbances are also important for increasing resilience in managed systems and promoting community well-being. These include maintaining forest infrastructure (e.g. road network) to allow a swift and targeted response to unfolding bark beetle outbreaks (Seidl et al. 2016), building relationships with local residents at the preparedness stage, and keeping good communication with all stakeholders involved in outbreak management by using participatory approaches (see Appendix A).

\subsection{High conservation value forests}

High conservation value forests (HCVF) are natural forest ecosystems or forests under protection for which the primary aim is to protect biodiversity, ecosystems and natural processes. These areas are not congruent with Natura 2000 areas, where a wide variety of management measures is regularly applied. Most HCVF forests are categorized as Wilderness Areas (cat. Ia, Ib) or as National Parks (cat. II) according to the IUCN. Other HCVF include small strictly protected reserves embedded in production forest landscapes.

In Europe, $38 \%$ of protected areas in IUCN categories I and II are stocked with Norway spruce (Hagge et al. 20I8), and may thus face infestation of Ips typographus. Management of HCVF follows different considerations than for production forests which are managed to optimize market values and societal demands. Specifically, the impact of bark beetles in HCVF must be considered in concert with objectives such as the preservation of endangered species, protection of natural processes, quality of recreational experiences, and provisioning of ecosystem services such as clean drinking water.

For HCVF it is important to distinguish between three kinds of bark beetle outbreaks that may require different management responses:

- Outbreaks of native bark beetles, such as Ips $t y$ pographus, within the natural range of their host tree species. Co-evolution of host tree, beetle and many other species has occurred, which means active management is rarely required. Native insects 
are part of the natural system, contribute to natural ecosystem dynamics and often increase biodiversity. This holds even under climate change, because in the past these ecosystems experienced conditions that favoured bark beetles even more.

- Outbreaks of bark beetle species that expand their native range (e.g. as a result of climate change). Range expansion might critically impact conservation values and push ecosystems out of their natural dynamics. It may be necessary to consider management options to reduce the impact.

- Outbreaks of invading bark beetle species from other parts of the world. Invasive species can seriously damage forests of high conservation value. Coordinated nationwide or international actions might be required to contain the invasion or to deploy resistant tree genotypes, as was done for American chestnut following the introduction of a fungal pathogen into North America.

\section{Native bark beetles with positive effects on biodiversity}

Managers of HCVF sometimes underappreciate the dynamic nature of forests, and specifically the important role recurring natural disturbances play in the conservation of biodiversity. This lack of dynamic thinking often results in unrealistic expectations regarding the natural share of mature and oldgrowth stands in the landscape.

An example of the growing awareness of the importance of natural disturbances for forest dynamics is the large fires that occurred in Yellowstone National Park in the US in I988. Following these fires, research documented the importance of fire for maintaining natural ecosystem processes, and this helped change public attitudes towards natural disturbances and their management within the park. Similar research findings emerged in Europe following the massive outbreak of Ips typographus in the Bavarian Forest National Park in the I990s (Thorn et al. 20I7). Broadly speaking, early successional forest habitats were identified as being highly valuable for biodiversity conservation. Specifically, a large number of species, including several threatened species, were found to be adapted to early successional stages following bark beetle outbreaks, windstorms, and fires. Even species that were previously considered specialists of over-mature stands, such as the capercaillie Tetrao urogallus, were found to thrive in heterogeneous landscapes after disturbances.
Recent analyses indicate that bark beetle outbreaks create heterogeneous tree cover patterns, which lead to structurally more complex forests that provide excellent habitat for species favouring such complexity. For example, the small hazel grouse Tetrastes bonasia inhabits dense vegetation with many pioneer tree species, but also uses tall trees and forest gaps with bare ground in their territory. Another example is the barbastelle bat Barbastella barbastella. In spruce forests this species roosts in bark pockets of bark beetle-killed trees in locations surrounded by living trees, and it prefers to hunt in stands with reduced tree stocking levels due to bark beetle attack.

In summary, intervention in HCVF following bark beetle outbreaks is usually not beneficial from a biodiversity perspective. On the contrary, in some HCVF the EU has designated certain species as focal species for conservation (Natura 2000) and management has to consider the needs of these species. The potential negative effects of intervention must be considered, for example, if the focal species live under the bark of beetle-killed trees or feed on insects on such trees. These issues have been raised in the recent debate about sanitary felling in the Białowieża forest, where woodpeckers and endangered beetle species such as Cucujus cinnabarinus or Pytho kolwensis feed under the bark of beetle-killed trees.

\section{Native bark beetles that threaten focal species for conservation}

Sometimes large-scale stand-replacing bark beetle outbreaks in HCVF can threaten local populations of species of conservation concern. The smaller the area and the more homogenous the forest landscape, the greater the threat. One example from the USA is the endemic squirrel Tamiasciurus hudsonicus grahamensis, whose population declined sharply following a large outbreak of the mountain pine beetle. The squirrel population still persists, but due to repeated disturbances involving bark beetles and wildfires it has recently shrunk to only 35 individuals, with a high probability of extinction (Koprowski pers. com.). Another example is the endangered red-cockaded woodpecker Leuconotopicus borealis which is native to North America. An essential habitat feature for the survival of this woodpecker is a constant supply of living, overmature pines with decayed heartwood. Bark beetle attack has been found to be a major cause of mortality of such cavity trees, disrupting the supply. These examples show 
that stand-replacing tree mortality caused by bark beetles can cause a decline in endangered species, particularly in small HCVF. However, for Norway spruce forests in Europe there are no reports to date that bark beetles may threaten species of conservation concern.

Bark beetles that expand their range into new areas A new problem in some HCVF is that bark beetle species expand their outbreak range into higher altitudes or latitudes in response to climate change. This may enable them to attack evolutionarily naïve or semi-naïve host trees, i.e. trees with little or no prior contact with the beetle over recent evolutionary history and which therefore lack effective defences. One example is the upward shift of mountain pine beetle in North America into whitebark pine forests without strong co-evolved defence against attacks (Raffa et al. 2013). This has resulted in high tree mortality that reduces the availability of whitebark pine cones as a food source for grizzly bears and other wildlife, as well as multiple other adverse environmental impacts. In Europe, the potential range expansion of Ips duplicatus might increase the pressure on Norway spruce, both inside and outside HCVF. However, since the beetle is native to Europe and attacks spruce in a similar way as Ips typographus its spread will result in competition between the two Ips species for host trees. Therefore, it is unlikely that Ips duplicatus will increase the risk of bark beetle outbreaks. Another example is the range expansion of Ips typographus in northern Europe in response to the extension of the growing season (see Chapter 2). This might change the disturbance regimes and forest developmental pathways for HCVF in northern Europe, but currently no immediate conservation threats are known from this range expansion.

\section{Non-native bark beetles invading areas of high conservation value}

A new challenge for HCVF may be disturbances resulting from invasions of non-native insects and pathogens. A well-known recent example is the emerald ash borer Agrilus planipennis, a buprestid from Asia now extirpating Fraxinus trees and threatening associated biodiversity in vast areas of North America. While single trees can be protected by repeated systemic pesticides in urban areas, no management tools are currently available at the stand or landscape scale. Similarly, the bark beetle Dendroctonus valens and its symbiotic fungi exert only minor impacts in their native range in North America, but are now causing widespread mortality to Chinese pines following their accidental introduction into China. Also, the bark beetle vector of the fungus causing Dutch elm disease, Scolytus multistriatus, completely transformed North American elm ecosystems following the introduction of this pathogen which is innocuous in its native range. Because most of these invasions happen on large spatial scales, the management options available for HCVF are limited. To date, no devastating invasive pests have emerged in Europe's Norway spruce forests.

Options for bark beetle management in small HCVF Relict stands of old trees in Europe are often very small in size. These old trees and stands are highly valued by conservationists and the public and are regularly under strict protection. Consequently, active management tools, such as insecticide application, anti-aggregant pheromones or glue trapping, are occasionally used to protect individual trees of high conservation value from bark beetle attack even in conservation areas. The motivation for such treatment is to protect valuable trees, or to reduce hazards from dead trees or limbs in frequented recreational areas. Other reasons include the protection of individual trees that show potential as sources of germplasm resistant against invasive pests. For example, whitebark pine trees surviving the invasive blister rust are protected against the range-expanding mountain pine beetle to conserve this genetic resource. However, such protective management is typically restricted to relatively few trees due to its high cost, and these measures are not practical for protecting forests across a large landscape.

Options for bark beetle management in large HCVF The most common approach for managing tree-killing native bark beetle attacks in larger protected areas is similar to the approaches used in production forests, e.g. sanitation logging (Müller et al. 20I8). Recently, however, several studies underlined the adverse impacts of these management activities on conservation goals, including: the loss of native species; a shift in community assembly processes; reduced natural regeneration; and the loss of key structures, such as abundant deadwood and old legacy trees surviving the disturbance. 
A global survey revealed that sanitation felling is frequently implemented in protected areas, particularly in Europe and Asia (Müller et al. 2018), and that the practice is widely accepted by the general public. Globally, green forests have important symbolic and aesthetic value for most people, while natural disturbances are commonly perceived as chaotic, messy and catastrophic. The recent public debate about sanitation harvesting in the Białowieża forest in Poland or the Monarch butterfly reserve in Mexico is an exception rather than the rule. Interestingly, the primary motivation for sanitation felling in protected areas is often similar to that in production forests, particularly in Europe and Asia, despite the strongly diverging management objectives (Müller et al. 20I8). Timber access and pest control are the two main motivations that are most frequently given also in HCVF.
A widespread approach for managing the European spruce bark beetle has been zoning, with a non-intervention zone at the core of the protected area, buffered by a management zone of sufficient width to avoid bark beetle population spread into surrounding managed forests (Kautz et al. 20II). Interestingly, recent research indicates that large, unmanaged HCVF often attract more bark beetles from the surrounding managed forests than they export (Montano et al. 20I6). Another approach regularly applied in HCVF areas is debarking of infested trees, destroying the brood of the European spruce bark beetle, but leaving the deadwood in the forest. This approach is very expensive, and has negative effects on a broad community of organisms colonizing bark beetle-infested trees. For the conservation of biodiversity, bark-scratching is a more suitable approach than debarking, and has also economic and scenic advantages (Hagge et al. 20I8). 


\section{Regional perspectives}

To show the diversity of environments where bark beetle outbreaks are occurring, as well as outbreak triggers, management approaches and impacts, we present here three examples of large-scale bark beetle outbreaks in Europe and North America. The three cases have occurred at different spatial scales - regional, national and continental - and illustrate different impacts and management responses specific to these scales.

\subsection{Storm Gudrun in Southern Sweden}

On 7-9 January 2005, storm Gudrun hit Europe, following a track from the northern United Kingdom, via southern Sweden and Denmark to the Baltic countries. The storm caused several casualties, and damaged forests, buildings and infrastructure, including the power supply to large areas. Southern Sweden was worst hit, with an estimated damaged wood volume of 75 million $\mathrm{m}^{3}$ (SFA 2006), making it the most damaging weather event ever recorded in Sweden. The felled volume equalled the normal annual harvest amount in all of Sweden, while in the worst-hit regions the damage was 20 times higher than the annual harvest. About II0,000-I30,000 ha was damaged to such an extent that regeneration was required by law. The storm affected about 4 million ha, and 272,000 ha were classified as damaged or severely damaged. Norway spruce made up about $80 \%$ of the windfelled volume.

A massive effort was made to quickly remove felled and damaged trees from the forest, in order to reduce timber quality losses and prevent an outbreak of the spruce bark beetle. Measures included tax reductions on sold wood, reduced wood transportation fees, tax-free diesel for forest machinery, and subsidies on storage of wood. Temporary programmes were set up to monitor bark beetle

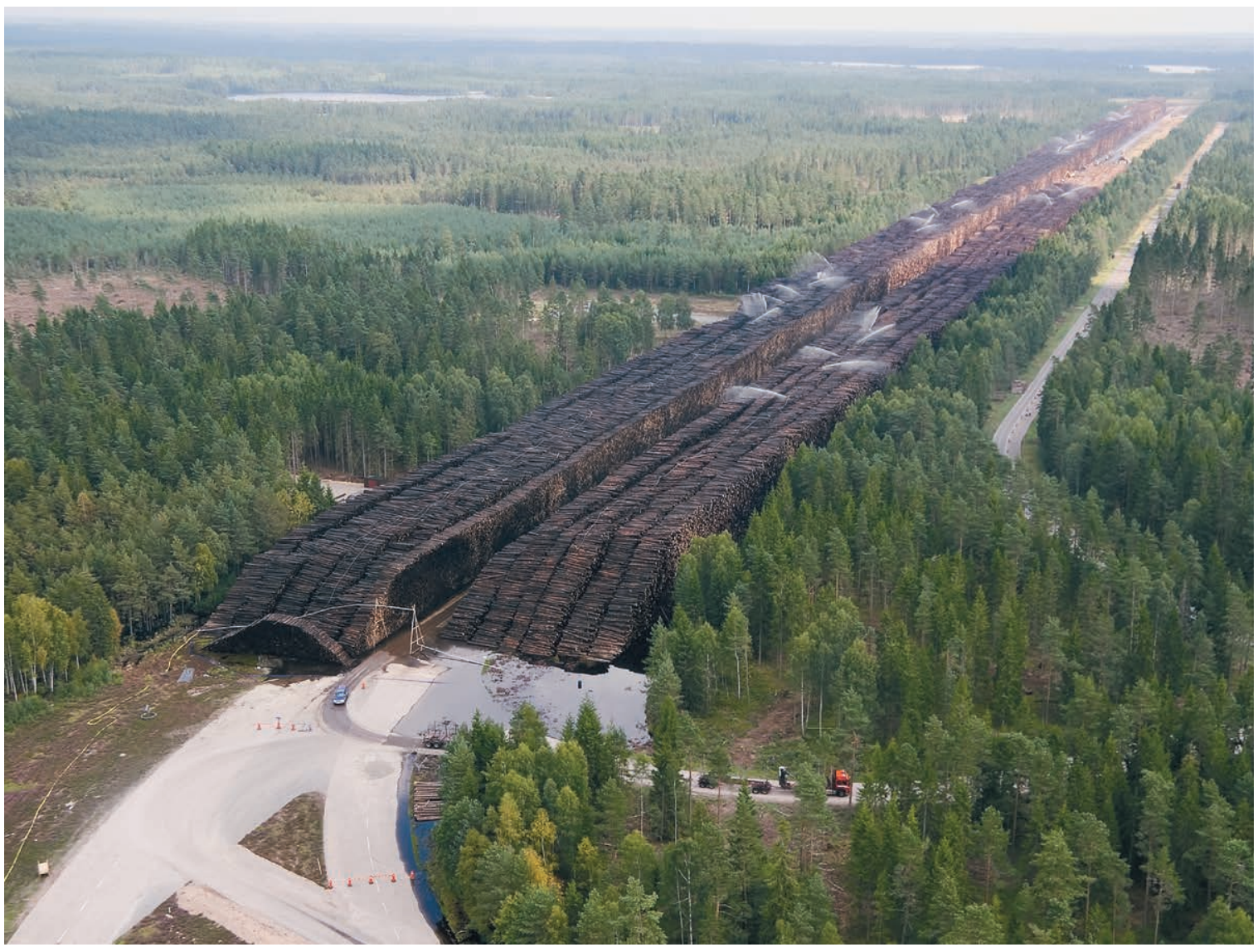

Figure 13. One million cubic meters of spruce blown down by storm Gudrun in Sweden in 2005, stacked on an abandoned airfield in Southern Sweden. Photo: Thomas Adolfsén / Skogenbild. 
infestations, and new regulations to combat insect infestations were put in place in 2007.

Although the salvage and sanitation felling progressed more quickly than anticipated, about $13 \%$ of the felled volume remained in the forest at the end of 2005, and beetle populations and tree mortality increased dramatically in 2006. The summer of 2006 was warmer than normal in southern Sweden and allowed the beetles to complete two successful generations for the first time in recorded history. Despite this - and an additional I2 million $\mathrm{m}^{3}$ storm damage in early 2007 - beetle-induced tree mortality was lower than expected in 2007 and 2008 , and by 2009 the outbreak was collapsing. Overall, about 3 million $\mathrm{m}^{3}$ of spruce was killed by the bark beetles during 2006-2008. The reasons for the rapid collapse of the beetle outbreak are not fully known. One contributing factor may be that the trees felled by the 2007 storm acted as trap trees, as they were largely salvaged before the bark beetles had emerged from the freshly thrown and infested logs.

The price of spruce timber decreased from about 40 euro per $\mathrm{m}^{3}$ in the years before 2005 to about 25 euro per $\mathrm{m}^{3}$ in 2005 . The total additional costs to the forest sector due to storm Gudrun have been estimated at I.I-I.2 billion euro. Less wind damage was reported in nature conservation areas than in production forests. Probably due to time pressure and poor information flow, procedures for logging in biodiversity conservation areas were often not followed, and several nature conservation objects were destroyed in the salvaging operations (SFA 2006).

\section{The preparedness of the Nordic countries}

It is noteworthy that legislation and other actions have contributed to efficiently prevent or mitigate large bark beetle damage in the Nordic countries over the last four decades. An essential backbone of disturbance management in all Nordic countries is the relatively dense forest road network that facilitates small-scale forest management and early removal of infested trees. However, warmer summers and faster beetle development have highlighted the need to update current forestry legislation and management instructions, such as instructions on the timing of management operations. Moreover, a decreasing number of civil servants responsible for transferring scientific knowledge to legislation and management may reduce the efficiency of outbreak management in the near future. Formal transboundary collaboration between the Nordic countries on disturbance management is not well developed and there is no common policy or strategy to tackle the foreseen climate change-induced alterations in forest disturbance regimes.

\subsection{Western Beskids in Central Europe}

The Western Beskids is one of the most important regions of forest decline in Europe. This 9,500 $\mathrm{km}^{2}$ Slovak-Czech-Polish transboundary region is covered mostly by intensively managed coniferous forests of homogenous age and species structure. The region borders the so-called Black Triangle, an industrial cluster that badly affected forest health before 1990 by air pollution, with some effects persisting until now. A body of evidence suggests that local forests were weakened by several interacting factors, including long-term acid depositions, nutrient degradation and adverse effects of climate (e.g. Cienciala et al. 20I7). These factors are assumed to have compromised tree defences and increased tree susceptibility to bark beetle attack. Forest vulnerability was also amplified by an overly homogenous forest structure resulting from clear-cutting management and repeated planting of several generations of spruce.

The most recent bark beetle outbreak, which involved mainly Ips typographus, started around 2002 and culminated in 2009-2010. However, highly elevated beetle activity persists to the present, and the outbreak has thus been going on for more than $\mathrm{I} 5$ years. Tree death from bark beetle infestation has been further amplified by extensive fungal infection (mainly by Armillaria white rot) and occasional windthrows and snow breakages. A broader region of the Slovak part of Western Beskids experienced an increase in the amount of salvaged volume from $0.2-0.5$ million $\mathrm{m}^{3}$ in the period $1996-2000$ to 2.0 -2.4 million $\mathrm{m}^{3}$ in the period 20I4-20I7. While salvage and sanitation logging accounted for $40-50 \%$ of total harvests in the former period, it accounted for up to $95 \%$ of total harvests in the latter period.

Extensive trapping and logging operations (both salvage and sanitary) were applied throughout the most recent outbreak. The current management strategy strives to slow down the progress of forest decline, reduce economic losses, regenerate disturbed stands and enhance the resilience of the 
new forest. Still, despite all management efforts the outbreak persists and continues to expand due to the homogenous forest structure and a climate that is more and more favourable for bark beetles. Coordinated transboundary cooperation to manage the outbreak has not been established.

Because the Beskids region is dominated by forests managed for timber production, intensive outbreak management has not caused much public involvement or concerns about nature conservation, in contrast to what has recently occurred elsewhere. The outbreak has had catastrophic impacts on the regional forestry economy. Huge amounts of salvaged timber could not be sold, but accumulated in storage yards and often acted as an additional breeding source for the beetles. Roundwood was sold as fuelwood and the income of private forest owners or enterprises rapidly declined. The great demand for forest workers and a generally low unemployment rate increased labour costs, adding further challenges to the region's declining forestry economy.

In addition to the economic impacts of the bark beetle outbreak, local residents reported very negative perceptions of the visual changes to their traditionally forested environment. This echoes responses reported from other outbreak regions, such as the Bavarian Forest National Park (Müller 20II). There are no reports of deteriorating air and water quality, or impacts on tourism following the Beskids outbreak.

The outbreak in the Western Beskids has long been thought of as a geographically isolated event, but currently unprecedented bark beetle disturbances are challenging the future of spruce-oriented forestry in all countries in the region. This is especially true for the Czech Republic, where the amount of salvaged timber from bark beetle outbreaks is in creasing dramatically; from 5.3 million $\mathrm{m}^{3}$ in $20 \mathrm{I} 7$ to I8 million in 2018 , with forecasts for the next few years indicating that the annual salvage may reach I5-30 million $\mathrm{m}^{3}$. The massive supply of salvaged timber has caused a dramatic drop in timber prices, from c. 55 euros per $\mathrm{m}^{3}$ in $20 \mathrm{I} 7$, to c. 15 euros in 2018 (standing timber price). The drop in timber prices and lack of capacity to process the immense amounts of salvaged timber further hampers the effective outbreak management. The current out break is affecting mainly managed forests, and forests both within and outside the natural distribution of Norway spruce. The recent outbreak has thus questioned some broadly held assumptions about predisposing factors for bark beetle outbreaks, and highlighted the increasing risk of outbreak synchronization over large geographical areas.

\section{The preparedness of some central European countries}

In general, management of forest disturbances in central European countries such as the Czech Republic, Slovakia and Poland is strongly influenced by traditional forestry approaches, with insufficient focus on adaptation to climate change, including further disturbance intensification and the emergence of novel pests. The importance of pheromone traps in controlling bark beetle outbreaks is still overestimated, and there is little use of tools such as integrated forecasting or hazard rating systems based on analysis of data on pest occurrence and trends in disturbed areas, meteorology or remote sensing data.

National crisis plans for cross-sectoral cooperation (including economy, transportation, forestry, public safety and environment) are not sufficiently operational to allow for early and effective mitigation of large-scale disturbances. Still, the recent large-scale windthrows and beetle outbreaks have, for example in the Czech Republic, resulted in a higher degree of political mobilization, including cross-sectoral cooperation, subsidy policies and constructive dialogue between government and environmental NGOs. A general strategy adopted to cope with intensifying bark beetle outbreaks has been to improve procedures for early identification (e.g. using drones) and processing of infested trees (e.g. debarking), and increasing the capacity for massive salvage and sanitation operations. Although there is increasing recognition of the risks related to spruce-oriented forest management at all levels of forest management, management responses are still not sufficient to meet the challenges. The harvesting rate of overmature vulnerable stands is too low, the conversion of monospecific stands happens too slowly, and there is insufficient promotion of silvicultural practices that enhance forest resilience.

\subsection{Mountain pine beetle in the Rocky Mountains of North America}

Concurrent with outbreaks in Europe, several even larger bark beetle outbreaks have been affecting North America. Much has been learned about 


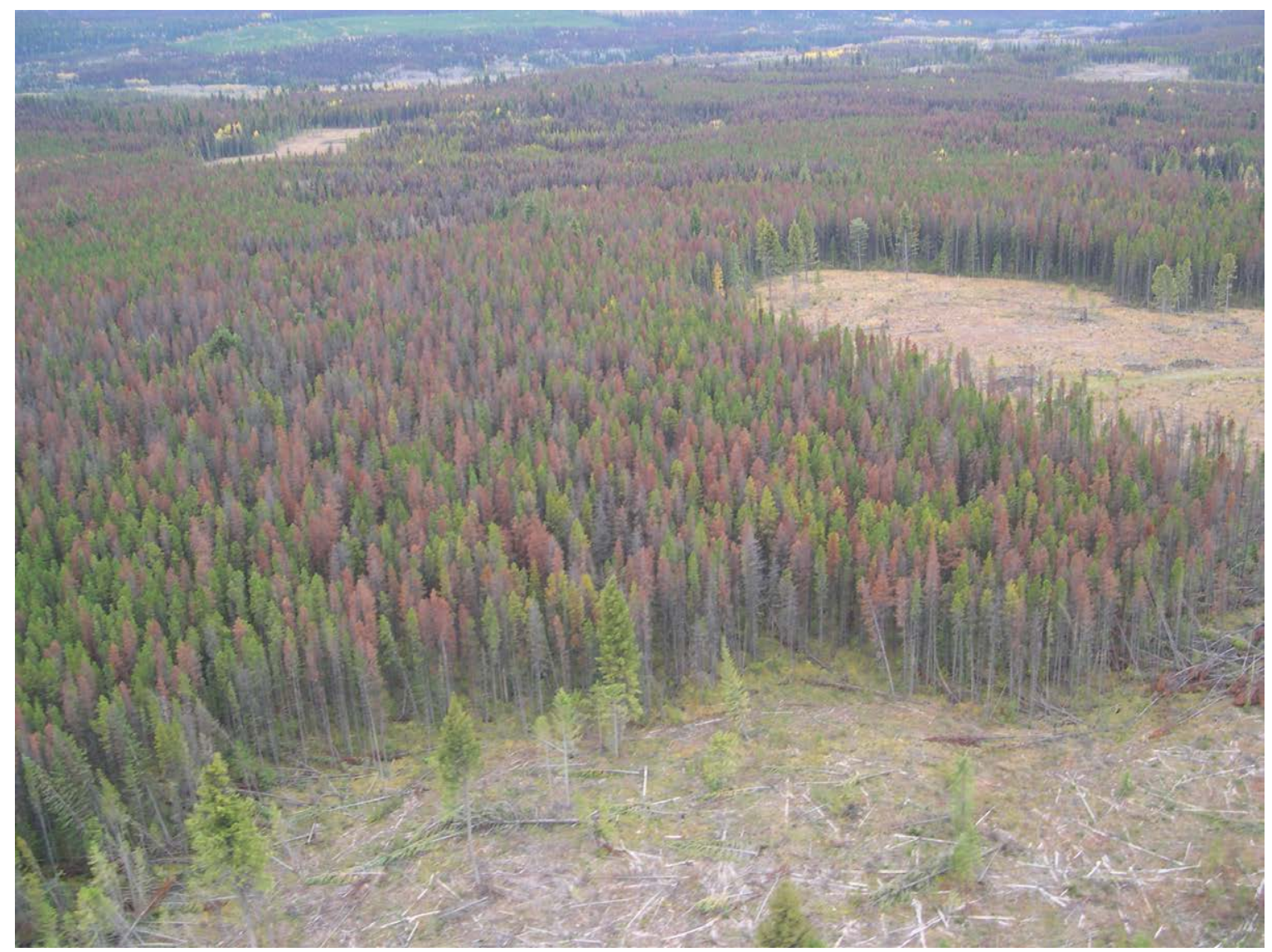

Figure 14. Aerial photo of lodgepole pines killed by the mountain pine beetle in British Columbia. Sanitation cutting can be seen in foreground. Photo: Kenneth Raffa.

outbreak dynamics, basic biology, environmental and economic impacts, and management following these outbreaks, so some insights are provided here. The mountain pine beetle, Dendroctonus ponderosae is native to the pine forests of western North America. These expansive forests tend to be relatively low in species diversity and are managed primarily for multiple-use purposes such as timber production, recreation, and grazing (often on government land), and in some areas as wilderness (roughly equivalent to the high conservation value forests of Europe). Intermittent synchronous outbreaks have occurred across much of this region over recent centuries (Jarvis and Kulakowski 20I5). These outbreaks, along with wildfires, represent important natural disturbances that play key stand replacement roles.

The area of mountain pine beetle outbreaks in the US was of unprecedented size, totalling 6.6 million ha during $1980-2000$ alone, continuing until 2005 over large areas and until 2017 in some areas. The area affected exceeded that of wildfires during this period. Impacts in western Canada have been even higher, with over I8 million ha damaged, resulting in a loss of approximately 723 million $\mathrm{m}^{3}$ by 2012 ( $53 \%$ of total merchantable pine volume). The recent outbreaks included regions that were previously climatically too cold for populations to reach outbreak levels. This includes higher latitudes in British Columbia and high elevations dominated by whitebark pine, Pinus albicaulis, a native species with relatively little recent historical exposure to bark beetles and less pronounced defences than the traditional host species. The beetle also expanded its geographic range by breaching the geophysical barrier of the Rocky Mountains into Alberta, entering stands dominated by jack pine, Pinus banksiana lodgepole pine hybrids, and subsequently pure jack pine. This range expansion is unprecedented and raises concerns that outbreaks might continue eastward into new regions where non-adapted host species are relatively poorly defended.

Factors driving mountain pine beetle outbreaks are complex and are related to both host factors, 
such as stand density and tree vigour, and climatic factors influencing beetle survival and reproduction (Raffa et al. 2008). The relative extents to which various factors explain the onset and scale of outbreaks vary, but include a combination of climate change effects on beetle reproduction, fire suppression and historical cutting practices contributing to the creation of highly susceptible stands. Adjoining wilderness areas have also been suggested to be a major source of the recent outbreak, but the spatiotemporal patterns more strongly support large-scale synchronous drivers such as climate (Aukema et al. 2006).

Managing mountain pine beetle is challenging given the enormous scale of outbreaks. Silvicultural approaches, mostly reducing tree density, can lower stand susceptibility and thus constrain populations below their epidemic threshold. To be effective, these approaches must be applied over relatively large areas and before outbreaks develop. Removal of infested trees can be implemented to reduce populations during outbreaks, but these methods require intensive survey and rapid mobilization to remove trees before beetles emerge. Recently, the Canadian Forest Service has aggressively suppressed populations in Alberta as they first appear, to prevent this beetle's eastern spread into new regions. Although expensive, this appears to slow the spread. A variety of measures have been used to protect individual, high value trees (e.g. in high-use recreation areas), ranging from pesticides to anti-aggregant pheromones, with varying degrees of success.

Western North American forests are impacted by several other bark beetle species that may also undergo large-scale outbreaks. These species vary in their ability to kill vigorous trees once their populations pass the epidemic threshold, versus remaining limited to colonizing stressed trees. Notably, the transcontinentally distributed North American spruce beetle (Dendroctonus rufipennis), undergoes largescale outbreaks in naturally homogeneous forests, but not in more species-rich regions. Even following large-scale windthrows in more species-rich forests, the high diversity and abundance of bark and phloem feeding insects can exert such high competition (Haberkern et al. 2002) that population increases of D. rufipennis remain relatively localized and of marginal impact. Another North American bark beetle that can exhibit landscape-scale outbreaks and kill healthy trees is the southern pine beetle (Dendroctonus frontalis). However, in recent decades these outbreaks have largely decreased. Host trees are commonly grown in commercial plantations in which other features of intensive management, such as routine thinning, short-rotation harvesting, vegetation management, sanitation, and aggressive monitoring, outweigh the population-enhancing features of tree species- and age- homogeneity. 


\section{Policy implications and recommendations}

\subsection{Policy implications}

Native bark beetles are important for the functioning of natural forest ecosystems, as they contribute to nutrient cycling and biodiversity. However, a few bark beetle species may undergo intermittent landscape-scale outbreaks and thus interfere with forest management objectives. Bark beetle outbreaks have significant economic implications along the whole forest-related value chain as well as important social impacts. There is also ample evidence that bark beetle outbreaks negatively impact ecosystem service provisioning.

Synchronized by extreme weather, recent bark beetle outbreaks have already reached a supranational scale. There is also ample evidence that climate change will further increase forest disturbance from bark beetles in Europe, and outbreaks may also expand to new regions. Outbreaks are likely to further increase in extent and severity in the future, and effective mitigation of their impacts will require coordinated international action. Unfortunately, European countries are insufficiently prepared for intensifying bark beetle outbreaks and other shifts in forest disturbance regimes. Current outbreak management is often dominated by ad hoc decisions with limited scientific backing and little stakeholder involvement. Consequently, an increase in social conflicts arising from intensifying bark beetle outbreaks is likely. Furthermore, conflicting views on appropriate management options for disturbed forests and a limited public acceptance of natural disturbances in forest ecosystems prevail.

Integrative outbreak responses that include monitoring, sanitation, silviculture and non-intervention are still poorly developed. This is alarming, since current risk reduction approaches are expected to become less efficient with climate change. Moreover, most currently practiced management responses to bark beetle outbreaks have poorly documented effectiveness, but are being applied widely. Alternative approaches, such as non-intervention in the face of bark beetle outbreaks, are a neglected management option in many European countries, even in situations where salvage logging is not economically viable and sanitation logging is unlikely to supress outbreaks.
Non-native bark beetle species have become established in Europe at an accelerating rate. Many of these species are still expanding their range and their ultimate impact is not yet known. In general, there is no coordinated monitoring of invasive bark beetles in Europe, and no effective preparedness plans are in place for eradication of newly detected species. A framework for more coordinated efforts to prevent, detect and eradicate invading species is provided by the recently enacted EU Regulation on Invasive Alien Species, which is highly applicable to the management of invading bark beetles.

Current management practices in high conservation value forests do not sufficiently consider the positive effects bark beetle disturbances may have on landscape heterogeneity and biodiversity. Also, the high capacity of naturally disturbed forests to recover without human intervention is largely underestimated.

Several gaps exist in our understanding of bark beetle outbreak mechanisms, their impacts and the management responses to them. For example, our current understanding of the social dimensions of bark beetle disturbances is insufficient to adequately inform forest management and policy. More research is needed to assess the ability of sanitation measures to reduce damage, result in net economic benefits, and limit negative environmental impacts.

\subsection{Policy recommendations}

Efficient outbreak management requires that bark beetles are recognized as a natural part of forest ecosystems, and that whether they are considered to result in damage or provide benefits depends on local management objectives. To efficiently manage bark beetle outbreaks, it is necessary to explicitly define management objectives, which will often require participatory approaches that engage multiple stakeholders. A clear set of management objectives that is accepted by a broad group of stakeholders will also reduce the probability of societal conflicts. Reaching this objective might require implementing improved education and communication programmes at all administrative levels, from governments to local area managers. This would help to provide better and updated information 
and rectify possible misconceptions about natural disturbances.

The management of bark beetle outbreaks under climate change requires a balance between risk reduction approaches, which have dominated forest management in Europe, and measures that foster forest resilience, i.e. the ability of forest to recover after disturbance and maintain forest functioning. The latter becomes increasingly important under bark beetle outbreaks that are fuelled by climate change and may potentially reach extents and in tensities that are beyond the control of management measures that were successfully applied in the past.

The management of large-scale outbreaks requires strengthened international collaboration on forest protection, pest monitoring and forest management. Cross-sectoral crisis management plans (including the forestry, environment, finance, transportation and public safety sectors, among others) are necessary to mitigate the adverse effects of outbreaks for forest owners and society. Platforms such as the European Forest Institute (EFI) Risk Facility can provide efficient support in developing coordinated international disturbance management strategies.

The mitigation of conflicts caused by some recent outbreaks and the efforts to manage them requires abandoning the frequent practice of using ad hoc solutions that may lack both consensus and consistency. Building relationships with local communities and acknowledging their concerns will help identify management strategies that are supported by local stakeholders and should be prioritized in future outbreak management efforts. This involvement should be based on further research on the ecological and social dimensions of bark beetle outbreaks. More knowledge on these issues is urgently needed to fill gaps in our current understanding, and is likely to lead to the development of more efficient pest management strategies.

Effective management of bark beetle outbreaks requires a holistic, landscape-scale and evidence-based approach that integrates monitoring, sanitation, silviculture and non-intervention. The following aspects need to be considered in this process:

- Adopt legislation that supports the implementation of a broader spectrum of forest protection methods and measures, thereby increasing the flexibility of managers to develop bark beetle management strategies that are tailored to their specific management objectives and environments.

- Relax legal constraints on forest management that interfere with a more comprehensive approach to disturbance management. The requirement that disturbed sites must be regenerated within a short time window, for instance, often leads to the creation of homogeneous and even-aged young stands, which will again be highly susceptible to natural disturbances in the future.

- Create administrative structures that allow for disturbance management at the landscape scale. This includes, for example, improved coordination and communication between forest owners (e.g. via owner associations) to support efforts to disrupt the connectedness of beetle populations and host trees across the landscape.

- Facilitate the sharing of data on pests and diseases collected by national forest protection agencies and similar bodies. Create a consistent international monitoring system for bark beetles in Europe.

- Given the high potential for negative impacts of invasive alien bark beetles, a network of attractant-baited traps should be installed across Europe for early detection (and subsequent eradication) of invading species. Regulations that help to control and prevent the spread of non-native barkand woodboring insects via the international trade of roundwood and wood packaging should be imposed.

- Recognize disturbances as opportunities to adapt forests to changing environmental conditions. Changing the tree species composition, e.g. of secondary coniferous forests, to more site- and climate-adapted species mixtures has long been on the political agenda in Central Europe. However, the on-site implementation of these goals has been slow. Recent large-scale disturbances provide opportunities to initiate more robust and diverse stands, and facilitate the adaptation of these forests to emerging environmental conditions.

- Support forest owners in their efforts to generate diverse stands after outbreaks (e.g. via targeted subsidy programmes).

- Revise the current interpretation of sanitation and salvage logging in view of the emerging scientific understanding of their effectiveness (or lack thereof), to prevent inefficient use of resources, 
undesired collateral impacts and misuse of existing policy instruments (such as reduced tax on logs from sanitation logging).

- Reconsider the widespread use of mass-trapping to control bark beetle populations, particularly during epidemic conditions. Instead, install and maintain trap-based pest monitoring systems. 


\section{Glossary}

Community context refers to the socioeconomic and biophysical features of local places that generally influence interactions between people and the environment.

Disturbance regimes describe the frequencies, sizes and severities of disturbance over extended spatial and temporal scales that are typical for a landscape. They often comprise the interplay of different disturbance agents, such as wind and bark beetles.

Disturbance legacies are organisms, organic materials and patterns that persist through a disturbance and influence the rate and trajectory of post-disturbance development.

Ecosystem services are benefits that humans derive from ecosystems. Four categories of ecosystem services can be distinguished: provisioning services, such as the production of food, fibre and water; regulating services, such as the control of climate and diseases; supporting services, such as nutrient cycles and oxygen production; and cultural services, such as spiritual and recreational benefits.

Forest disturbances are discrete events that dramatically alter the structure, composition and function of an ecosystem, community or population and change resource availability or the physical environment. Prominent examples in Europe's forests are wildfires, insect outbreaks or windthrow events.

Quarantine species are species against which quarantine measures need to be taken (often regulated by law). Quarantine measures include, for instance, the treatment of wood packaging material to prevent the spread of pests in wood, or the removal and burning of all infested plant material.

Salvage logging is the practice of harvesting dead, dying, damaged, or weakened trees to recover economic losses from natural disturbances.

Note: Salvage logging and sanitation logging (below) are colloquially often used interchangeably, and in actual operation may overlap.

Sanitation logging is the harvesting of trees for the purpose of removing insects or diseases. 


\section{References}

The report used knowledge from more than 250 literature sources. For the sake of clarity, we have reduced the reference list and included only the most relevant references.

Abdullah, H. et al. (20I8) European spruce bark beetle (Ips typographus, L.) green attack affects foliar reflectance and biochemical properties. International Journal of Applied Earth Observation and Geoinformation 64: 199-209. https://doi.org/10.1016/j.jag.2017.09.009

Aukema, B. H. et al. (2006) Landscape level analysis of mountain pine beetle in British Columbia, Canada: spatiotemporal development and spatial synchrony within the present outbreak. Ecography 29: 427-44I. https://doi.org/IO.IIII/j.2006.0906-7590.04445.x

Beudert, B. et al. (2OI5) Bark beetles increase biodiversity while maintaining drinking water quality. Conservation Letters 8: 272-28I. https://doi.org/IO.IIII/conl.I2I53

Black, S. H. et al. (2013) Do bark beetle outbreaks increase wildfire risks in the Central U.S. Rocky Mountains? Implications from recent research BioOne Complete 33: 59-65. https://doi.org/I0.3375/043.033.0107

Bogdanski B., et al. (20II) Markets for forest products following a large disturbance: opportunities and challenges from the mountain pine beetle outbreak in western Canada. Canadian Forest Service. Pacific Forestry Centre. Information Report BC-X-429, 69p.

Čada, V. et al. (20I6) Frequent severe natural disturbances and non-equilibrium landscape dynamics shaped the mountain spruce forest in central Europe. Forest Ecology and Management 363: I69-I78. https://doi. org/I0.I0I6/j.foreco.20I5.I2.023

Cienciala, E. et al. (20I7) Recent spruce decline with biotic pathogen infestation as a result of interacting climate, deposition and soil variables. European Journal of Forest Research 136: 307-317. https://doi.org/I0.I007/ SIO342-0I7-1032-9

Cohen, J. et al. (2016) Hedonic valuation with translating amenities: mountain pine beetles and host trees in Colorado front range. Environmental and Resource Economics 63:613-642. https://doi.org/I0.1007/ sio640-014-9856-y

Dhar, A. et al., (2016) Consequences of mountain pine beetle outbreak on forest ecosystem services in western Canada. Canadian Journal of Forest Research 46: 987-999. https://doi.org/Io.Ir39/cjfr-2016-oI37

Flint, C. G. \& Luloff, A. E. (2007) Community activeness in response to forest disturbance in Alaska. Society and Natural Resources 20: 43I-450. https://doi.org/I0.I080/0894I92070I2II850

Galko, J. et al. (20I6) Effectiveness of pheromone traps for the European spruce bark beetle: a comparative study of four commercial products and two new models. Forestry Journal 62: 207-215. https://doi.org/I0.1515/ forj-2016-0027

Griess, V.C. et al. (2012) Does mixing tree species enhance stand resistance against natural hazards? A case study for spruce. Forest Ecology and Management 267: 284-296. https://doi.org/Io.IoI6/j.foreco.20I2.02.008

Haberkern, K.E. et al. (2002) Bark beetles and fungal associates colonizing white spruce in the Great Lakes region. Canadian Journal of Forest Research 32: II37-II5O. https://doi.org/IO.II39/xO2-033

Hagge, J. et al. (2018) Reconciling pest control, nature conservation and recreation in coniferous forests. Conservation Letters: eІ26I5. https://doi.org/IO.IIII/conl.I26I5

Hantula, J. et al. (20I4) International plant trade associated risks: Laissez-fair or novel solutions? Environmental Science and Policy 37: I58-I60. https://doi.org/I0.I0I6/j.envsci.20I3.09.0II

Henne, P.D. et al. (2015) Reviving extinct Mediterranean forests increases ecosystem potential in a warmer future. Frontiers in Ecology and the Environment 13: 356-362. https://doi.org/10.1890/150027

Hilmers, T. et al. (2018) Biodiversity along temperate forest succession. Journal of Applied Ecology 55: 27562766. https://doi.org/I0.IIII/1365-2664.13238

Hlásny, T. et al. (20I7) Conversion of Norway spruce forests in the face of climate change: a case study in Central Europe. European Journal of Forest Research I36: IOI3-IO28. https://doi.org/IO.IOO7/sIO342-0I7-IO28-5

Holling, C.S. (1973) Resilience and stability of ecological systems. Annual Review of Ecology, Evolution and Systematics 4: I-23. https://doi.org/I0.1046/j.I523-I739.1996.10020328.x 
Holling, C.S. \& Meffe, G.K. (I996) Command and control and the pathology of natural resource management. Conservation Biology Io: 328-337.

Holmes, T.P. (I99I) Price and welfare effects of catastrophic forest damage from Southern pine beetle epidemics. Forest Science 37: 500-516.

Jactel, H. et al. (2009) The influences of forest stand management on biotic and abiotic risks of damage. Annals of Forest Science 66: 70I-70I. https://doi.org/10.1051/forest/2009054

Jarvis, D. S. \& Kulakowski, D. (20I5) Long-term history and synchrony of mountain pine beetle outbreaks in lodgepole pine forests. Journal of Biogeography 42: I029-1039. https://doi.org/IO.IIII/jbi.I2489

Jönsson, A. M. et al. (20II) Modelling the potential impact of global warming on Ips typographus voltinism and reproductive diapause. Climatic Change ı09: 695-7I8. https://doi.org/10.1007/sı0584-0II-0038-4

Kärvemo, S. et al. (20I6) Local colonization-extinction dynamics of a tree-killing bark beetle during a largescale outbreak. Ecosphere 7: eоI257. https://doi.org/ı0.1002/ecs2.I257

Kautz, M. et al. (2OII) Quantifying spatio-temporal dispersion of bark beetle infestations in epidemic and non-epidemic conditions. Forest Ecology and Management 262: 598-608. https://doi.org/ıo.Ioi6/j.foreco.20II.04.023

Kautz, M. et al. (20I4) Individual traits as drivers of spatial dispersal and infestation patterns in a host-bark beetle system. Ecological Modelling 273: 264-276. https://doi.org/ro.ror6/j.ecolmodel.20I3.II.022

Kirkendall, L. R. \& Faccoli, M. (2010) Bark beetles and pinhole borers (Curculionidae, Scolytinae, Platypodinae) alien to Europe. ZooKeys 56: 227-251. https://doi.org/10.3897/zookeys.56.529

Leverkus, A.B. et al. (20I8) Salvage logging effects on regulating and supporting ecosystem services — a systematic map. Canadian Journal of Forest Research 48: 983-1000. https://doi.org/Io.II39/cjfr-2018-oII4

Loeffler, D. \& Anderson, N. (20I7) Impacts of the mountain pine beetle on sawmill operations, costs, and product values in Montana. Forest Products 68: 15-24.

Marini, L. et al. (2OI2) Climate affects severity and altitudinal distribution of outbreaks in an eruptive bark beetle. Climatic Change II5: 327-34I. https://doi.org/ı0.1007/sio584-012-0463-z

Marini, L. et al. (20I7) Climate drivers of bark beetle outbreak dynamics in Norway spruce forests. Ecography 40: I426-I435. https://doi.org/IO.IIII/ecog.02769

Montano, V. et al. (20I6) How differential management strategies affect Ips typographus L. dispersal? Forest Ecology and Management 360: 195-204. https://doi.org/10.1016/j.foreco.2015.10.037

Mori, A.S. et al. (2013) Response diversity determines the resilience of ecosystems to environmental change. Biological Reviews 88: 349-364. https://doi.org/I0.IIII/brv.I2004

Müller, J. et al. (20I8) Increasing disturbance demands new policies to conserve intact forest. Conservation Letters I2: eI2449. https://doi.org/IO.IIII/conl.I2449

Müller, M. (20II) How natural disturbance triggers political conflict: bark beetles and the meaning of landscape in the Bavarian Forest. Global Environmental Change 21: 935-946. https://doi.org/Io.IoI6/j.gloenvcha.2011.05.004

Neuner, S. et al. (20I4) Survival of Norway spruce remains higher in mixed stands under a dryer and warmer climate. Global Change Biology 2I: 935-946. https://doi.org/IO.IIII/gcb.I275I

Parkins, J. R. \& MacKendrick, N. A. (2007) Assessing community vulnerability: a study of the mountain pine beetle outbreak in British Columbia, Canada. Global Environmental Change I7: 460-47I. https://doi. org/ı.1016/j.gloenvcha.2007.01.003

Pohjola, J. et al. (20I8) Immediate and long-run impacts of a forest carbon policy - A market-level assessment with heterogeneous forest owners. Journal of Forest Economics 32: 94-105. https://doi.org/10.1016/j. jfe.2018.03.00I

Potterf, M. \& Bone, C. (20I7) Simulating bark beetle population dynamics in response to windthrow events. Ecological Complexity 32: 2I-30. https://doi.org/10.10I6/j.ecocom.20I7.08.003

Powell, E.N. et al. (20I2) Wildfire provides refuge from local extinction but is an unlikely driver of outbreaks by mountain pine beetle. Ecological Monographs 82: 69-84. https://doi.org/I0.I890/II-0607.I

Pye, J. et al. (20II) Economic impacts of the southern pine beetle. Chapter I4 in Southern Pine Beetle II, Coulson, R. N.; Klepzig, Kier; General Technical Report (GTR)-SRS-I4O. Asheville, NC: U.S. Department of Agriculture Forest Service, Southern Research Station, 2I3-222. 
Qin, H. \& Flint, C. G. (2010) Capturing community context of human response to forest disturbance by insects: a multi-method assessment. Human Ecology 38: 567-579. https://doi.org/10.1007/sio745-0I0-9334-2

Qin, H. et al. (20I5) Tracing temporal changes in the human dimensions of forest insect disturbance on the Kenai Peninsula, Alaska. Human Ecology 43: 43-59. https://doi.org/10.1007/sI0745-0I4-97I7-X

Raffa, K. F. et al. (2008) Cross-scale drivers of natural disturbances prone to anthropogenic amplification: the dynamics of bark beetle eruptions. BioScience 58: 50I-5I7. https://doi.org/10.164I/b580607

Raffa, K. F. et al. (2013) Temperature-driven range expansion of an irruptive insect heightened by weakly coevolved plant defenses Proceedings of the National Academy of Science of the USA IIO: 2193-2I98. https:// doi.org/10.1073/pnas.I216666i1o

Rosenberger, R.S. et al. (2013) Estimating the economic value of recreation losses in the Rocky Mountain pine beetle outbreak. Proceedings of the Western economics forum: 3I-39.

Seidl, R. et al. (2OII) Unraveling the drivers of intensifying forest disturbance regimes in Europe. Global Change Biology I7: 2842-2852. https://doi.org/IO.IIII/j.I365-2486.2011.02452.x

Seidl, R. (20I4) The shape of ecosystem management to come: anticipating risks and fostering resilience. Bioscience 64: II59-II69. https://doi.org/I0.I093/biosci/biur72

Seidl, R. et al. (20I4) Increasing forest disturbances in Europe and their impact on carbon storage. Nature Climate Change 4: 806-810. https://doi.org/10.1038/nclimate2318

Seidl, R. et al. (20I6) Searching for resilience: addressing the impacts of changing disturbance regimes on forest ecosystem services. Journal of Applied Ecology 53: I2I-I29. https://doi.org/IO.IIII/I365-2664.I25II

Senf, C. \& Seidl, R. (20I8) Natural disturbances are spatially diverse but temporally synchronized across temperate forest landscapes in Europe. Global Change Biology 24: I20I-I2II. https://doi.org/IO.IIII/gcb.I3897

SFA (2006) Stormen 2005 - en skoglig analys. (In Swedish.) Meddelande Nr I Jönköping: Swedish Forest Agency.

SFA (20I0) Swedish statistical yearbook of forestry. Jönköping: Swedish Forest Agency.

Simard, M. et al. (20II) Do bark beetle outbreaks change the probability of active crown fire in lodgepole pine forests? Ecological Monographs 8I: 3-24. https://doi.org/I0.I890/10-II76.I

Sommerfeld, A. et al. (20I8) Patterns and drivers of recent disturbances across the temperate forest biome. Nature Communications 9: 4355. https://doi.org/10.1038/s41467-018-06788-9

Spiecker, H. et al. (eds.) (20I9) Douglas-fir - an option for Europe. What Science Can Tell Us 9, European Forest Institute, I2I p.

Temperli, C. et al. (2013) Cross-scale interactions among bark beetles, climate change, and wind disturbances: a landscape modeling approach. Ecological Monographs 83:383-402. https://doi.org/I0.I890/I2-I503.I

Thom, D. \& Seidl, R. (20I6) Natural disturbance impacts on ecosystem services and biodiversity in temperate and boreal forests. Biological Reviews 91: 760-78r. https://doi.org/Io.IIII/brv.I2I93

Thom, D. et al. (20I7) Disturbances catalyse the adaptation of forest ecosystems to changing climate conditions. Global Change Biology 23: 269-282. https://doi.org/IO.IIII/gcb.I3506

Thorn, S. et al. (20I6) Bark-scratching of storm-felled trees preserves biodiversity at lower economic costs compared to debarking. Forest Ecology and Management 364: I0-I6. https://doi.org/IO.IoI6/j.foreco.20I5.I2.044

Thorn, S. et al. (20I7) Effects of natural disturbances and salvage logging on biodiversity - Lessons from the Bohemian Forest. Forest Ecology and Management 388: II3-II9. https://doi.org/I0.IoI6/j.foreco.2016.06.006

Yoon, J.-S. et al. (2018) Double-stranded RNA binding protein, Staufen, is required for the initiation of RNAi in coleopteran insects. PNAS II5: 8334-8339. https://doi.org/10.1073/pnas.I80938III5

Wermelinger, B. (2004) Ecology and management of the spruce bark beetle Ips typographus—a review of recent research. Forest Ecology and Management 202: 67-82. https://doi.org/10.1016/j.forec0.2004.07.018

Zeppenfeld, T. et al. (2015) Response of mountain Picea abies forests to stand-replacing bark beetle outbreaks: neighbourhood effects lead to self-replacement. Journal of Applied Ecology 52: I402-I4II. https://doi. org/IO.IIII/I365-2664.12504

Zhang, Q-H. \& Schlyter, F. (2003) Redundancy, synergism and active inhibitory range of non-host volatiles in reducing pheromone attraction in European spruce bark beetle Ips typographus. Oikos IOI: 299-3I0. https:// doi.org/I0.I034/j.I600-0706.2003.III595.X 


\section{Appendix A: Tools and measures for managing bark beetle outbreaks}

This appendix contains a list of tools and measures reviewed in this report. The items are grouped by the four categories of the emergency management cycle, i.e. preparedness, prevention, response, recovery. This is a widely applied framework for managing risks to communities and the environment. Fig. I5 shows a simplified concept of the proposed "toolbox", while the following tables contain more detailed descriptions of individual tools and measures.

\section{Preparedness}

Improved education and training
Strengthened collaboration
Improved knowledge transfer
Strengthened dialogue

Prevention

Establishing early warning systems Improving landscape configuration Preventing invasions Reducing rotation Conducting proper forest sanitation
Improved forest roads Established monitoring programmes Increased capacity of nurseries Increased timber storage capacities

\section{Response}

Increasing salvaging efficiency

Reducing planned harvests

Subsidizing response measures

Improving communication

\section{Recovery}

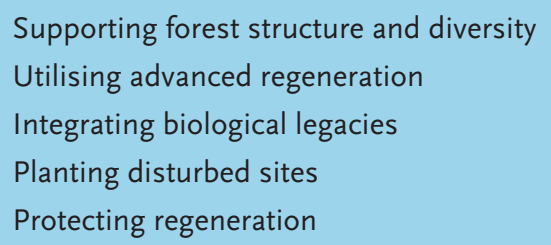

Figure 15. A simplified scheme of the toolbox for managing bark beetle outbreaks. 


\begin{tabular}{|c|c|c|}
\hline \multicolumn{3}{|r|}{ PREPAREDNESS } \\
\hline No. & Tools \& measures & Description \\
\hline 1.1 & Improving education & $\begin{array}{l}\text { In many parts of Europe traditional approaches to outbreak manage- } \\
\text { ment and perceptions of disturbances still dominate, often lacking } \\
\text { scientific foundation. This calls for the development of new curricula, } \\
\text { and intensive education and training at all levels of forest policy- and } \\
\text { decision-making. }\end{array}$ \\
\hline 1.2 & $\begin{array}{l}\text { Strengthening international } \\
\text { collaboration }\end{array}$ & $\begin{array}{l}\text { The transboundary scale of outbreaks and the potential introduction } \\
\text { and spread of new pests require strengthened international collabora- } \\
\text { tion in terms of data and knowledge sharing, pest monitoring and crisis } \\
\text { management. }\end{array}$ \\
\hline 1.3 & $\begin{array}{l}\text { Increasing knowledge transfer } \\
\text { and evidence-based deci- } \\
\text { sion-making }\end{array}$ & $\begin{array}{l}\text { Intensifying outbreaks increasingly question the efficiency of traditional } \\
\text { approaches to outbreak management. There is a need for improved } \\
\text { knowledge transfer from science to policy, legislation and practical } \\
\text { management, as well as the development of best practice examples, to } \\
\text { improve outbreak management. }\end{array}$ \\
\hline 1.4 & $\begin{array}{l}\text { Developing effective crisis } \\
\text { management programmes }\end{array}$ & $\begin{array}{l}\text { Outbreaks occuring at national or supranational scales require well-pre- } \\
\text { pared cross-sectoral responses (forestry, environment, finance, trans- } \\
\text { portation, public security, etc.). Instead, ad hoc solutions prevail today, } \\
\text { which often lack broader consensus and consistency, and are often a } \\
\text { source of social conflict. }\end{array}$ \\
\hline 1.5 & $\begin{array}{l}\text { Developing zonation for nature } \\
\text { conservation areas }\end{array}$ & $\begin{array}{l}\text { Landscape-level planning in nature conservation areas should include } \\
\text { adequate buffer zones preventing the dispersal of beetles into adjacent } \\
\text { managed forests. }\end{array}$ \\
\hline 1.6 & $\begin{array}{l}\text { Maintaining multi-stakeholder } \\
\text { dialogue }\end{array}$ & $\begin{array}{l}\text { Dialogue should be maintained with all stakeholders involved in } \\
\text { outbreak management or otherwise concerned with the forest and its } \\
\text { development to increase the efficiency of measures, acceptance of the } \\
\text { final outcome, and mitigate the risk of societal conflicts. }\end{array}$ \\
\hline 1.7 & $\begin{array}{l}\text { Building relationships with local } \\
\text { communities }\end{array}$ & $\begin{array}{l}\text { Building relationships with local communities and clearly communicat- } \\
\text { ing risks and potential counter-measures prior to outbreaks lends legiti- } \\
\text { macy to outbreak management and reduces the risk of societal conflicts. }\end{array}$ \\
\hline 1.8 & $\begin{array}{l}\text { Improving and/or establishing } \\
\text { systems for monitoring forest } \\
\text { susceptibility to disturbance } \\
\text { and the dynamics of pest pop- } \\
\text { ulations }\end{array}$ & $\begin{array}{l}\text { Timely and efficient implementation of management actions require } \\
\text { early detection of highly susceptible forest conditions, climatic extreme } \\
\text { events that could trigger pest outbreaks, increases in pest densities (e.g. } \\
\text { increased number of generations per year), or the appearance of new } \\
\text { pests. Most existing monitoring systems do not provide comprehensive } \\
\text { support to outbreak management, or are not used at all. }\end{array}$ \\
\hline 1.9 & $\begin{array}{l}\text { Maintain sufficient levels of } \\
\text { well-trained professionals }\end{array}$ & $\begin{array}{l}\text { Employment levels in forestry are going down, yet challenges - such as } \\
\text { dealing with bark beetle outbreaks - are increasing. To be prepared to } \\
\text { deal with these challenges it is important to have well-trained forestry } \\
\text { personnel on site who know the local conditions. }\end{array}$ \\
\hline 1.10 & $\begin{array}{l}\text { Supporting advanced regener- } \\
\text { ation }\end{array}$ & $\begin{array}{l}\text { Maintaining a vigorous advanced spruce regeneration facilitates a faster } \\
\text { recovery of forest cover after a disturbance event. }\end{array}$ \\
\hline 1.11 & $\begin{array}{l}\text { Maintain sufficient nursery } \\
\text { capacity }\end{array}$ & $\begin{array}{l}\text { Greatly increased demands on reproductive material of suitable species } \\
\text { and provenances after large-scale bark beetle disturbances may exceed } \\
\text { the existing capacity of nurseries and could result in insufficient regener- } \\
\text { ation of disturbed areas. }\end{array}$ \\
\hline 1.12 & $\begin{array}{l}\text { Developing and maintaining an } \\
\text { adequate forest road network }\end{array}$ & $\begin{array}{l}\text { A sufficient forest road network is needed for small-scale interventions, } \\
\text { resilience-oriented management, as well as efficient detection and } \\
\text { removal of infested trees. }\end{array}$ \\
\hline 1.13 & $\begin{array}{l}\text { Increasing timber storage } \\
\text { capacities }\end{array}$ & $\begin{array}{l}\text { Sufficient facilities for wet storage of timber function as a supply buffer } \\
\text { after windthrows and bark beetle outbreaks, by preventing large quanti- } \\
\text { ties of timber flooding the market. }\end{array}$ \\
\hline
\end{tabular}




\begin{tabular}{|c|c|c|}
\hline \multicolumn{3}{|r|}{ PREVENTION } \\
\hline No. & Tools \& measures & Description \\
\hline 2.1 & $\begin{array}{l}\text { Developing early-warning sys- } \\
\text { tems and integrating them in } \\
\text { outbreak management }\end{array}$ & $\begin{array}{l}\text { Development and maintainance of early warning systems based on near } \\
\text { real-time weather data, automated beetle monitoring, and/or remote } \\
\text { sensing data helps to identify areas with a high risk of bark beetle att- } \\
\text { acks, and to implement targeted prevention measures. }\end{array}$ \\
\hline 2.2 & $\begin{array}{l}\text { Coordinating beetle manage- } \\
\text { ment across the landscape }\end{array}$ & $\begin{array}{l}\text { Effective management of outbreaks is often complicated in multi-owner } \\
\text { landscapes. Plans for coordinated management actions across property } \\
\text { boundaries are needed to prevent outbreaks spreading. }\end{array}$ \\
\hline 2.3 & $\begin{array}{l}\text { Decreasing landscape-scale } \\
\text { host connectivity }\end{array}$ & $\begin{array}{l}\text { Aim to reduce the landscape-scale connectivity of susceptible hosts by } \\
\text { implementing targeted landscape management measures that contain } \\
\text { the spread of beetles from individual attack spots. }\end{array}$ \\
\hline 2.4 & $\begin{array}{l}\text { Using pheromone traps for } \\
\text { monitoring of beetle popula- } \\
\text { tions and potential invasion }\end{array}$ & $\begin{array}{l}\text { Pheromone traps can be efficiently used to monitor beetle populations } \\
\text { and inform management decisions on timing and intensity of control } \\
\text { measures. }\end{array}$ \\
\hline 2.5 & $\begin{array}{l}\text { Maintaining compositionally } \\
\text { and structurally diverse stands }\end{array}$ & $\begin{array}{l}\text { Mixed stands with a complex vertical and horizontal structure tend to be } \\
\text { less susceptible to pest infestations and generally exhibit a higher sur- } \\
\text { vival rate under compounding disturbances than monospecific stands } \\
\text { of homogeneous structure. }\end{array}$ \\
\hline 2.6 & Reducing the rotation period & $\begin{array}{l}\text { Tree vulnerability to wind and bark beetle damage increases with age } \\
\text { and tree size. Reducing the area of susceptible age classes reduces the } \\
\text { overall outbreak risk. }\end{array}$ \\
\hline 2.7 & $\begin{array}{l}\text { Increasing host tree resistance } \\
\text { by thinning }\end{array}$ & $\begin{array}{l}\text { Silvicultural treatments that reduce competition between trees can } \\
\text { increase tree vigour and resistance against bark beetles. }\end{array}$ \\
\hline 2.8 & Early detection of infested trees & $\begin{array}{l}\text { A prerequisite for efficient sanitation felling is the ability to detect infest- } \\
\text { ed trees early (in the green attack stage) using a range of terrestrial and } \\
\text { remote sensing approaches. }\end{array}$ \\
\hline 2.9 & $\begin{array}{l}\text { Reducing outbreak risks by } \\
\text { sanitation felling }\end{array}$ & $\begin{array}{l}\text { Removing infested trees from the forest while the beetle brood is still in- } \\
\text { side can reduce beetle populations, maintain forest health and decrease } \\
\text { outbreak risks. Sanitation harvest of windfelled trees to prevent the } \\
\text { build up of beetle populations is also effective. }\end{array}$ \\
\hline 2.10 & $\begin{array}{l}\text { Preventing beetle spread from } \\
\text { felled trees and logs }\end{array}$ & $\begin{array}{l}\text { Mechanical or chemical treatment of infested windfalls and logs can } \\
\text { prevent beetles from leaving the trees and infesting live trees. Another } \\
\text { option is the timely removal of infested trees from the forest. }\end{array}$ \\
\hline 2.11 & $\begin{array}{l}\text { Creating habitats for the natural } \\
\text { enemies of bark beetles }\end{array}$ & $\begin{array}{l}\text { Bark beetles have a number of natural enemies (birds, predatory bee- } \\
\text { tles, etc.). Creating diverse stands with favourable habitat conditions } \\
\text { for natural enemies can reduce beetle populations and reduce outbreak } \\
\text { risks. }\end{array}$ \\
\hline 2.12 & $\begin{array}{l}\text { Planting seedlings of non-native } \\
\text { species on disturbed sites }\end{array}$ & $\begin{array}{l}\text { Planting non-native tree species that are not suitable hosts for native } \\
\text { bark beetles can be considered in highly susceptible areas where the } \\
\text { pool of native tree species needs to be enriched. }\end{array}$ \\
\hline
\end{tabular}




\begin{tabular}{|c|c|c|}
\hline \multicolumn{3}{|r|}{ RESPONSE } \\
\hline No. & Tools \& measures & Description \\
\hline 3.1 & Salvage logging & $\begin{array}{l}\text { Removal of infested, windfelled or otherwise damaged trees with the } \\
\text { primary intention to recover economic losses. Salvaging needs to take } \\
\text { place before timber quality deteriorates. Potential negative impacts of } \\
\text { salvage logging on biodiversity should be considered. }\end{array}$ \\
\hline 3.2 & Reducing planned harvests & $\begin{array}{l}\text { A reduction of planned harvests can free up capacities for logging of } \\
\text { beetle-killed timber and mitigate adverse effects of the temporary timber } \\
\text { surplus on the market. }\end{array}$ \\
\hline $3 \cdot 3$ & Subsidizing response measures & $\begin{array}{l}\text { Responses to a large-scale bark beetle outbreak may require substantial } \\
\text { investments, which could exceed the capacity of forest owners. Sub- } \\
\text { sidizing timber transport, storage and other components of outbreak } \\
\text { management can mitigate economic impacts and increase the efficiency } \\
\text { of the response actions. }\end{array}$ \\
\hline 3.4 & $\begin{array}{l}\text { Considering 'no management' } \\
\text { as a possible response option }\end{array}$ & $\begin{array}{l}\text { No management needs to be considered as a possible response option } \\
\text { in situations where salvaging is not economically viable and extensive } \\
\text { sanitary felling, mass-trapping and other measures do not hold promise } \\
\text { to contain the outbreak. In such situations benefits from the retention } \\
\text { of biological legacies should be exploited. }\end{array}$ \\
\hline 3.5 & Sanitation logging & $\begin{array}{l}\text { Detection and removal of infested trees can be applied to prevent the } \\
\text { spread of infestations, particularly for small infestation spots. Trees } \\
\text { damaged by wind or other abiotic factors should be prioritized because } \\
\text { they have weakened defences against bark beetles and serve as multi- } \\
\text { pliers for beetle populations. Hazard-rating and other types of models } \\
\text { can be used to optimize sanitation felling and reduce the connectivity of } \\
\text { host trees and beetle populations. }\end{array}$ \\
\hline 3.6 & $\begin{array}{l}\text { Increasing multi-stakeholder } \\
\text { dialogue and communicating } \\
\text { response strategies to the } \\
\text { public }\end{array}$ & $\begin{array}{l}\text { Maintaining a good dialogue with all stakeholders involved in outbreak } \\
\text { management will improve the efficiency of control measures and the } \\
\text { acceptance of final outcomes. Use the media to communicate manage- } \\
\text { ment strategies and progress to the general public to raise awareness } \\
\text { and reduce the risk of negative responses towards management actions. }\end{array}$ \\
\hline
\end{tabular}




\begin{tabular}{|c|c|c|}
\hline \multicolumn{3}{|r|}{ RECOVERY } \\
\hline No. & Tools \& measures & Description \\
\hline 4.1 & Fostering diverse stands & $\begin{array}{l}\text { During the recovery phase there are excellent opportunities to influence } \\
\text { the tree species composition of the regeneration, thereby reducing the } \\
\text { vulnerability to future outbreaks. }\end{array}$ \\
\hline 4.2 & $\begin{array}{l}\text { Supporting advanced regener- } \\
\text { ation }\end{array}$ & $\begin{array}{l}\text { Advanced regeneration present on site should be spared during logging } \\
\text { operations, as it facilitates a faster recovery of the forest canopy and } \\
\text { restores the microclimate. }\end{array}$ \\
\hline $4 \cdot 3$ & $\begin{array}{l}\text { Harnessing early-successional } \\
\text { species }\end{array}$ & $\begin{array}{l}\text { Regeneration of early-successional species such as birch, poplar and } \\
\text { larch can swiftly establish a new canopy. Commercially more important } \\
\text { species can later be planted under this canopy. }\end{array}$ \\
\hline $4 \cdot 4$ & $\begin{array}{l}\text { Considering natural recovery } \\
\text { processes }\end{array}$ & $\begin{array}{l}\text { Forests have a high capacity to naturally recover from disturbances. } \\
\text { Low-cost natural stand recovery options can be considered in areas } \\
\text { where a speedy recovery of spruce forests is not of paramount impor- } \\
\text { tance and where locally relevant ecosystem services are also provided by } \\
\text { naturally regenerating tree species. }\end{array}$ \\
\hline $4 \cdot 5$ & $\begin{array}{l}\text { Planting seedlings on disturbed } \\
\text { sites }\end{array}$ & $\begin{array}{l}\text { Planting seedlings leads to a quicker recovery of tree cover and gives } \\
\text { more control over the future tree species composition. }\end{array}$ \\
\hline 4.6 & $\begin{array}{l}\text { Protecting the regeneration } \\
\text { against adverse effects }\end{array}$ & $\begin{array}{l}\text { Protection of seedlings against browsing and competing vegetation } \\
\text { improves the growth rate and quality (shape) of the trees. }\end{array}$ \\
\hline $4 \cdot 7$ & $\begin{array}{l}\text { Integrating disturbance legacies } \\
\text { into the recovering forest }\end{array}$ & $\begin{array}{l}\text { Disturbance legacies, such as remaining live trees and standing and } \\
\text { downed deadwood, can be integrated into the recovering forest rather } \\
\text { than being completely removed. Such legacies support the regenerating } \\
\text { tree cohort and increase the structural diversity of the recovering stand. }\end{array}$ \\
\hline 4.8 & $\begin{array}{l}\text { Reducing browsing by ungu- } \\
\text { lates }\end{array}$ & $\begin{array}{l}\text { Browsing by ungulates is a key limiting factor for regeneration of dis- } \\
\text { turbed forests in many parts of Europe. Ungulate densities should thus } \\
\text { be regulated to levels where they do not hamper a successful and swift } \\
\text { regeneration of desired tree species. }\end{array}$ \\
\hline 4.9 & $\begin{array}{l}\text { Maintaining multi-stakeholder } \\
\text { dialogue }\end{array}$ & $\begin{array}{l}\text { Maintaining the dialogue with all stakeholders involved in outbreak } \\
\text { management makes it possible to track changing risk perceptions and } \\
\text { responses. }\end{array}$ \\
\hline 4.10 & Forest insurance & $\begin{array}{l}\text { Forest owners can be insured against certain kinds of forest damage } \\
\text { and loss of future income in some countries (e.g. Finland and Norway). } \\
\text { This provides an effective distribution of economic risks from distur- } \\
\text { bances among forest owners. }\end{array}$ \\
\hline 4.11 & Subsidizing recovery measures & $\begin{array}{l}\text { Recovery from large-scale bark beetle outbreaks may require substantial } \\
\text { investments, which may exceed the capacity of forest owners. Recov- } \\
\text { ery actions can be made more efficient by subsidizing afforestation } \\
\text { with tree species mixtures, tree species that are well adapted to local } \\
\text { climates, protection measures against browsing, etc. }\end{array}$ \\
\hline
\end{tabular}




\section{Appendix B: Research, development and innovation needs}

This appendix summarizes research, development and innovation (RDI) needs, which emerged from the writing of this report.

\begin{tabular}{|c|c|}
\hline ID & RDI items \\
\hline 1 & Development of more robust scientific projections of long-term bark beetle risks in Europe. \\
\hline 2 & $\begin{array}{l}\text { Development and improvement of hazard rating, resource allocation and other types of models to support } \\
\text { outbreak management activities. This includes, for example, models for prioritization of areas to salvage, } \\
\text { optimization of storage and transportation infastructure, etc. }\end{array}$ \\
\hline 3 & $\begin{array}{l}\text { Development of a better understanding of drivers that promote the build-up and collapse of bark beetle popula- } \\
\text { tions, and use of this information to improve existing pest dynamics, hazard rating and other types of models. }\end{array}$ \\
\hline 4 & $\begin{array}{l}\text { Improvement of remote sensing-based methods for early detection of infested trees (i.e. before apparent } \\
\text { visual signs of infestation) and adoption of these methods in forestry practice. }\end{array}$ \\
\hline 5 & $\begin{array}{l}\text { Improvement and testing of methods for treatment of logs extracted for sanitation reasons such as debark- } \\
\text { ing, bark scratching or fumigation that minimize impacts on the environment and biodiversity to increase } \\
\text { the efficiency of sanitation logging. }\end{array}$ \\
\hline 6 & $\begin{array}{l}\text { Improvement of methods for wet and dry storage of salvaged trees to buffer impacts on timber markets } \\
\text { during large-scale outbreaks. }\end{array}$ \\
\hline 7 & $\begin{array}{l}\text { Development of standardized cost-benefit analyses related to the implementation of different disturbance man- } \\
\text { agement measures to better understand their efficiency to prevent the outbreaks and reduce the impacts. }\end{array}$ \\
\hline 8 & $\begin{array}{l}\text { Improvement of options for forest pest monitoring based on pheromone traps, including 'smart traps', } \\
\text { autonomous trap-based monitoring systems, etc. to improve our abilities for early detection and eradication } \\
\text { of new pests as well as for early detection of changes in intra- and inter-annual dynamics of native pests. }\end{array}$ \\
\hline 9 & $\begin{array}{l}\text { Development of models for prediction of the emergence of new bark beetle pests with climate change and } \\
\text { their migration pathways in Europe, to improve our abilities for early detection and eradication. }\end{array}$ \\
\hline 10 & $\begin{array}{l}\text { Development of internationally harmonized system for forest pest monitoring based on pheromone traps to } \\
\text { allow for early detection of invasions. }\end{array}$ \\
\hline 11 & $\begin{array}{l}\text { Development of a better understanding of bark beetle migration between managed and unmanaged areas to } \\
\text { improve options for bark beetle management in landscapes managed for multiple objectives. }\end{array}$ \\
\hline 12 & $\begin{array}{l}\text { Strengthen the research on efficiency and potential collateral impacts of the RNAi-based insecticides and } \\
\text { semiochemicals. }\end{array}$ \\
\hline 13 & $\begin{array}{l}\text { Development of a better understanding of new compensation measures for forest owners affected by bark } \\
\text { beetle outbreaks (insurance, payment for ecosystem services, etc.) to efficiently reduce the impacts and } \\
\text { facilitate recovery. }\end{array}$ \\
\hline 14 & $\begin{array}{l}\text { Synthesize existing research on the human dimensions of forest disturbance by insects through systematic } \\
\text { reviews and meta-analyses. }\end{array}$ \\
\hline 15 & $\begin{array}{l}\text { Development of an international research network for the human dimensions of forest insect disturbance to } \\
\text { coordinate future research efforts. }\end{array}$ \\
\hline 16 & $\begin{array}{l}\text { Development of a better understanding of patterns of economic winners and losers after bark beetle } \\
\text { outbreaks in European countries to better understand the social impacts of bark beetle disturbances and } \\
\text { options to mitigate them. }\end{array}$ \\
\hline
\end{tabular}



X e are living in a time of accelerated changes and unprecedented global challenges: energy security, natural resource scarcity, biodiversity loss, fossil-resource dependence and climate change. Yet the challenges also demand new solutions and offer new opportunities. The cross-cutting nature of forests and the forest-based sector provides a strong basis to address these interconnected societal challenges, while supporting the development of a European circular bioeconomy.

The European Forest Institute is an unbiased, science-based international organisation that provides the best forest science knowledge and information for better informed policy making. EFI provides support for decision-takers, policy makers and institutions, bringing together cross-boundary scientific knowledge and expertise to strengthen science-policy dialogue.

This work and publication has been financed by EFI's MultiDonor Trust Fund for policy support, which is supported by the Governments of Austria, Czech Republic, Finland, Germany, Ireland, Italy, Lithuania, Norway, Spain and Sweden.

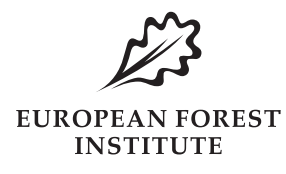

www.efi.int 